W/O 31171

SSS-TR-91-12978

\title{
ANALYSIS OF DIAGNOSTIC TESTING OF GLADYS McCALL WELL NO. 1
}

\author{
T. D. Riney \\ S. K. Garg
}

Preliminary Topical Report

Work Performed for

U.S. Department of Energy

Geothermal Division

Under Subcontract to

Lawrence Berkeley Laboratory

DOE/LBL Contract No. DE-AC03-76SF00098

\section{December 1991}

P.O. Box 1620, La Jolla, California, 92038-1620

(619) 453-0060 


\section{DISCLAIMER}

This report was prepared as an account of work sponsored by an agency of the United States Government. Neither the United States Government nor any agency Thereof, nor any of their employees, makes any warranty, express or implied, or assumes any legal liability or responsibility for the accuracy, completeness, or usefulness of any information, apparatus, product, or process disclosed, or represents that its use would not infringe privately owned rights. Reference herein to any specific commercial product, process, or service by trade name, trademark, manufacturer, or otherwise does not necessarily constitute or imply its endorsement, recommendation, or favoring by the United States Government or any agency thereof. The views and opinions of authors expressed herein do not necessarily state or reflect those of the United States Government or any agency thereof. 


\section{DISCLAIMER}

Portions of this document may be illegible in electronic image products. Images are produced from the best available original document. 


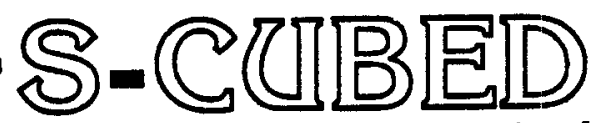

A Division of Maxwell Laboratories, Inc.

W/O 31171

SSS-TR-91-12978

\title{
ANALYSIS OF DIAGNOSTIC TESTING OF GLADYS MCCALL WELL NO. 1
}

\author{
T. D. Riney \\ S. K. Garg
}

Preliminary Topical Report

Work Performed for

U.S. Department of Energy

Geothermal Division

Under Subcontract to

Lawrence Berkeley Laboratory

DOEILBL Contract No. DE-AC03-76SF00098

\section{December 1991}

P.O. Box 1620, La Jolla, California, 92038-1620

(619) 453-0060 


\section{Introduction}

Gladys McCall Well No. 1 was flow tested from 1983 to $198 \%$, underwent long-term pressure buildup testing from October 1987 to October 1991, and has recently been re-entered for final diagnostic testing. The combination of a very large, poorly defined reservoir with data from only a single well has required that the testing be carried out over an unusually long time period for an understanding of the pressure maintenance mechanisms to be developed.

Ongoing diagnostic testing of the well has been undertaken by DOE to help resolve questions that arose during the analysis of the test data from the eight year depletion and recovery testing. A rather complete summary of the synthesis, correlation and analysis of the earlier test data has recently been published (Riney, 1991) and is included in this report as an Appendix. Figure 1 (an update of Figure 9 in the Appendix) includes the final pressure buildup data in the comparison with the earlier reservoir simulation model.

During October 1991 the Gladys McCall well was flowed twice as part of the diagnostic testing. On October 1 flow was started to clean out the well and to pierform a spinner survey to determine the fluid entry distribution across the perforated interval of Sand 8 . The spinner $\log$ was run on October 2 with the well producing at a constant rate of $\sim 4800 \mathrm{stb} / \mathrm{d}$. Total production during the October 1-2 test period was 5954 stb. The second flow was from October 10 to 14 to obtain downhole pressure transient data to determine if the transmissivity (kh product) of Sand 8 had changed during the four-year shutin period (October 1987 to October 1991). The total production during the four day constant-rate (5958 stb/d) drawdown test of October $10-14$ was 23,850 stb.*

Eaton Operating Co. and Institute of Gas Technology are continuing with the diagnostic testing; entry and pressure measurements in two overlaying sands (2 and 4) are planned. Since neither time nor funds are sufficient to complete the Gladys McCall analysis under S-Cubed's FY1991 Subcontract, this is a preliminary report. It is anticipated that the work will continue under a new FY1992 Subcontract to LBL.

\section{Diagnostic Test Data}

IGT has described the test system used during the October 1991 flow testing, summarized the fluid production rates and surface recordings during the tests, and interpreted the data from the spinner log (Randolph, et al., 1991). Our analysis utilizes the IGT data report and the downhole pressure transient data provided by Eaton Operating Company (EOC).

\footnotetext{
*In the Appendix flow rates are given in separator barrels per day (sep b/d) as reported at that time. Here we present flow rates in standard barrels per day (stb/d) as reported by IGT. The corresponding formation factors are $B=0.984 \mathrm{res}$ bbls $/ \mathrm{sep}$ bbls and $B_{0}=1.043 \mathrm{res}$ bbls $/ \mathrm{std}$ bbls $\left(B_{1}=B / B_{0}=0.944 \mathrm{std} \mathrm{bbls} / \mathrm{sep} \mathrm{bbls}\right)$.
} 


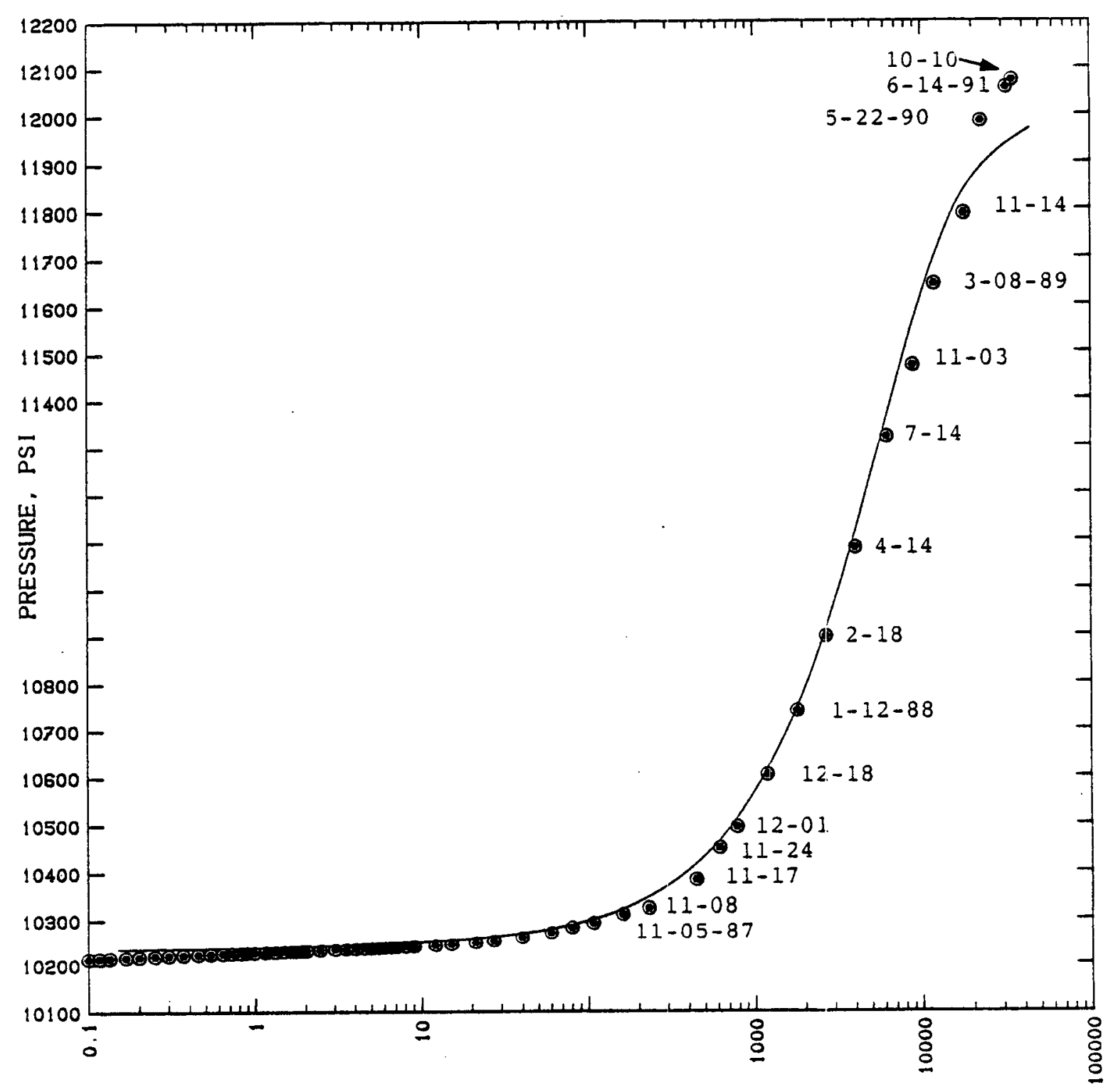

TIME MINUS $3.55988 E+04$, HOURS

Figure 1. Updated comparison of simulated pressure buildup history (curve) compared with bottomhole pressure data (points). Datum level is 15,100 feet. Model described in Appendix. 
IGT's interpretation of the spinner log data provides the following estimates for the percent of flow entering the Gladys McCall wellbore in each indicated interval of Sand 8 $(15,158-15,490$ feet $)$ :

\begin{tabular}{|rl||lr|}
\hline $5,150-15,200$ & $19.5 \%$ & $15,300-15,350$ & $5.3 \%$ \\
$15,200-15,250$ & $18.0 \%$ & $15,350-15,400$ & $15.9 \%$ \\
$15,250-15,300$ & $20.3 \%$ & Eielow 14,400 & $21.0 \%$ \\
\hline
\end{tabular}

The results indicate that at the time of the measurement (October 2,1991) there is communication with the wellbore both above and below the shale stringer located near the middle of Sand 8 at the wellbore (See Figure 2 in the Appenclix).

A Panex P/T gauge was lowered to 15,160 feet in the cleaned out, shutin well on October 09, 1991 and allowed to stabilize overnight. The stable pressure and temperature values recorded at 15,160 feet were

$$
P=12,096 \text { psia } \quad T=294.4^{\circ} \mathrm{F} \text {. }
$$

The well was opened to flow at 10:57:24 on October 10 and flowed at a steady rate of 5958 stb/d until shutin at 11:01:37 on October 14,1991. Bottomhole pressure and temperature were recorded by Milton L. Cooke during the $\sim 96$ hours of drawdown and for $\sim 46$ hours of buildup subsequent to shutin. At the time of shutin the flowing pressure and temperature values recorded at 15,160 feet were

$$
P_{w f}=11,981 \mathrm{psia} \quad T_{w f}=294.7^{\circ} \mathrm{F} .
$$

Figure 2 presents a cartesian plot of the continuously recorded bottomhole pressures during both the drawdown and buildup phases of the "Lliagnostic Test" (corrected to the common datum level of 15,100 feet).

Attempts to monitor the pressure buildup by isolated bottomhole $\mathrm{P} / \mathrm{T}$ logs were made on October 19 (11:25), October 31 (15:44) and November 04 (13: 59). Under normal field conditions errors in gauge placement can introduce error of about 25 psia. Since M. L. Cooke replaced the wireline prior to the last two logs, recorded depths for these measurements are highly suspect; the values reported for pressure at 15,160 feet on October 31 (12,109 psia) and November 04 (12,114 psia) are even larger than the stable pressure measured at that depth prior to starting the drawdown test $(12,096$ psia). It is likely that the new cable stretched under the wellbore conditions. In any case, the isolated P/T log recordings ane considered useless for analysis purposes. 


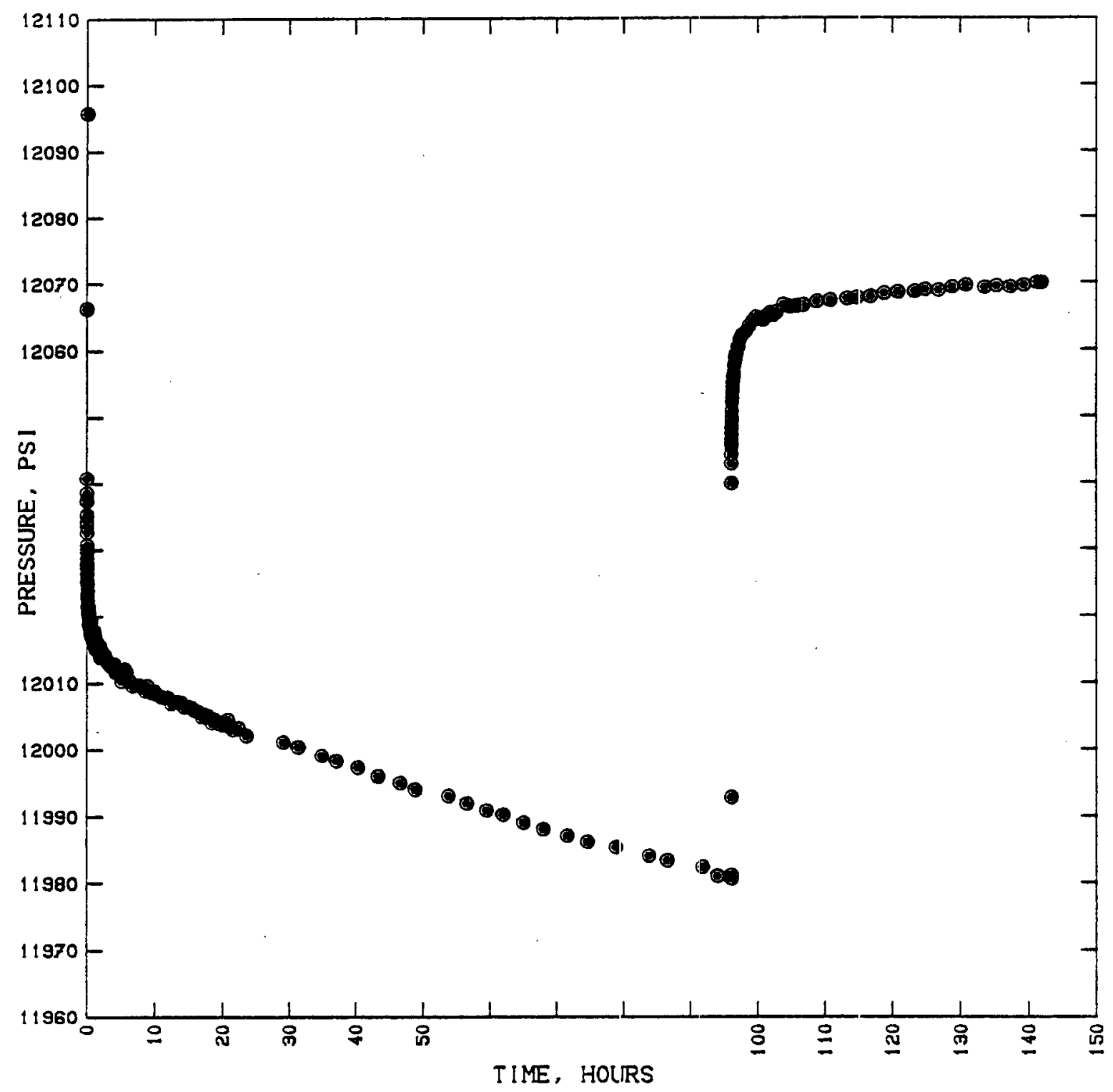

Figure 2. Bottomhole pressure transient data for Diagnostic Test. Data corrected to 15,100 feet datum level. 


\section{Preliminary Analysis}

Table 1 in the Appendix presents the results of the analysis of the four bottomhole pressure transient tests made prior to the Diagnostic Test. The value of kh at the time of the original 1983 Reservoir Limits Test (RLT) was much larger than the consistent values implied by the short-term bottomhole tests during 1985, 1986 and 1987. Figure 4 of the Appendix presents a semi-log plot of $\Delta p / \Delta q$ vs $\Delta t$ for each of the latter three tests. In Figure 3 a similar plot is presented which compares the measurements of the recent 1991 Diagnostic Test with the measurements from the RLT. It is apparent that these data plots approximate straight lines of about the same slope $\left[\mathrm{m}^{\prime}=1.19 \times 10^{-3} \mathrm{psi} / \sim(\mathrm{stb} / \mathrm{d})\right]$, and this slope is much smaller than the common slope of the lines approximating the data from three intervening pressure transient tests.

The spinner test has shown that Sand 8 is in communication with the wellbore above and below the shale stringer (near the center of Sand 8) as of October, 1991. Our earlier modeling work (Appendix) attributed the reduction in kh from the original RLT value to lower values during subsequent bottomhole pressure transient tests $(1985,1986$ and 1987) to partial plugging of Sand 8 during an aborted downhole scale inhibitor pill injection episode. Since there is no known mechanism for the plugging to have been removed during the long-term shutin test (November 1987-October 1991), our current analysis is re-examining all of the pressure transient data sets to evaluate the possibility that the variations in kh are caused by nonlinear changes in $k$ rather than changes in the effective value of $h$.

Nonlinear rock formation response effects might arise from overpressure hydraulic fracturing during the original drilling of the well or during the subsequent injection of scale inhibitor pills. Nonlinear formation response could also result from changes in the effective stress as the pore pressure is lowered during depletion and increased cluring recovery periods. In either case it is reasonable to assume that any nonlinear effects are largest in a near-well region since the pressure changes are largest near the wellbore. Moreover, the pressure excursions during each of the bottomhole pressure transient tests are small relative to the pressure changes during the total depletion/recovery phases of the Gladys McCall test history. This makes it reasonable to analyze the bottomhole pressure transient test results using linear semi-analytical methods even though the long-term depletion/recovery behavior might exhibit nonlinear response.

Figure 4 is a schematic of the composite cylindrical model useci in our ongoing analysis of each of the five bottomhole pressure transient tests at Gladys McCall. The solution contains the following two dimensionless ratios of formation parameters for the two regions of the composite reservoir

$$
\gamma=\left(k \varphi \mu c_{t}\right)_{2} /\left(k \varphi \mu c_{t}\right)_{1} \quad \delta=(\mathrm{kh} / \mu)_{2} /(\mathrm{kh} / \mu)_{1}
$$




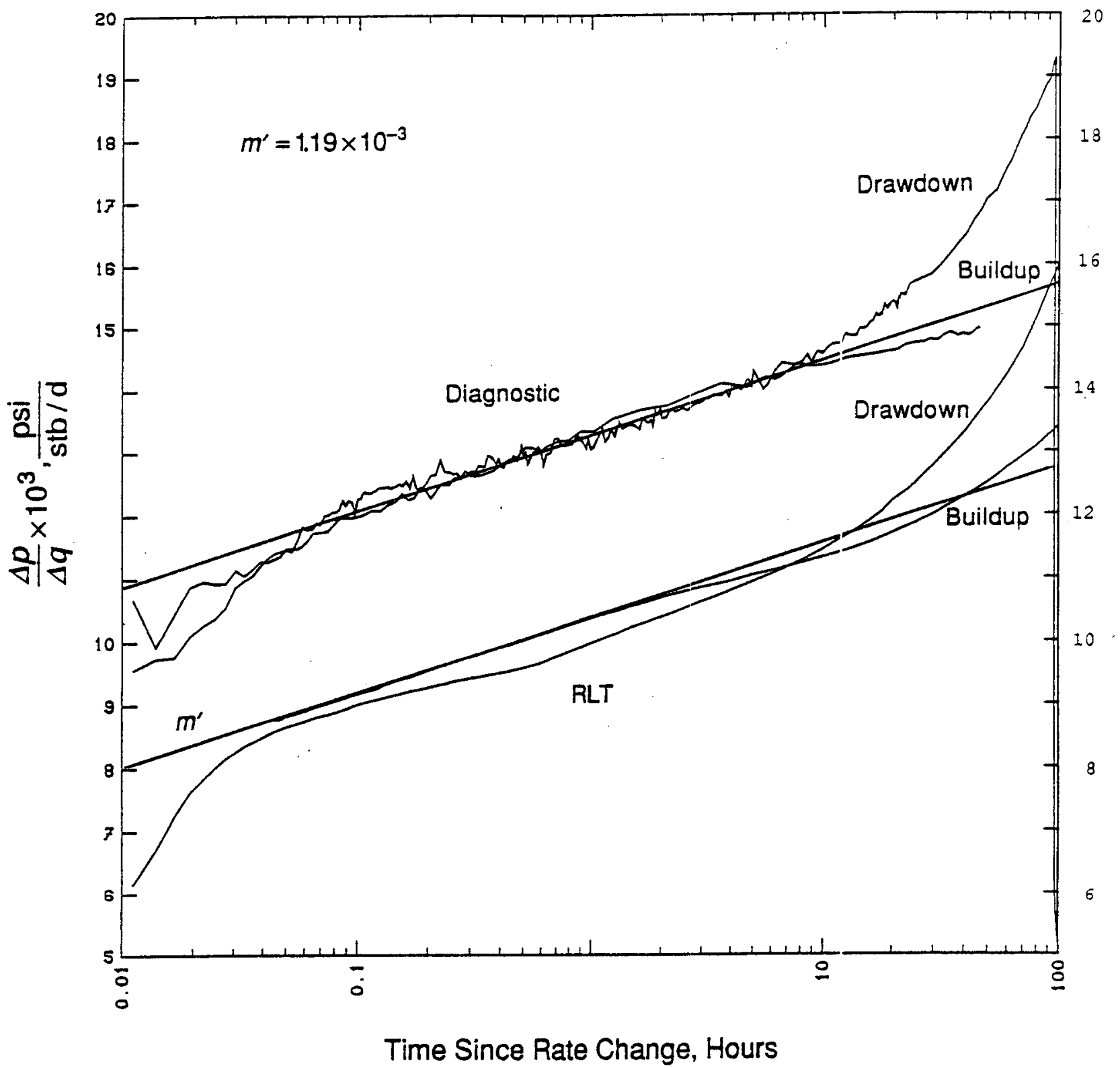

Figure 3. Bottomhole pressure transient data for 1983 RLT and 1991 Diagnostic Test. Vertical displacement reflects change in skin factor $(s)$. 


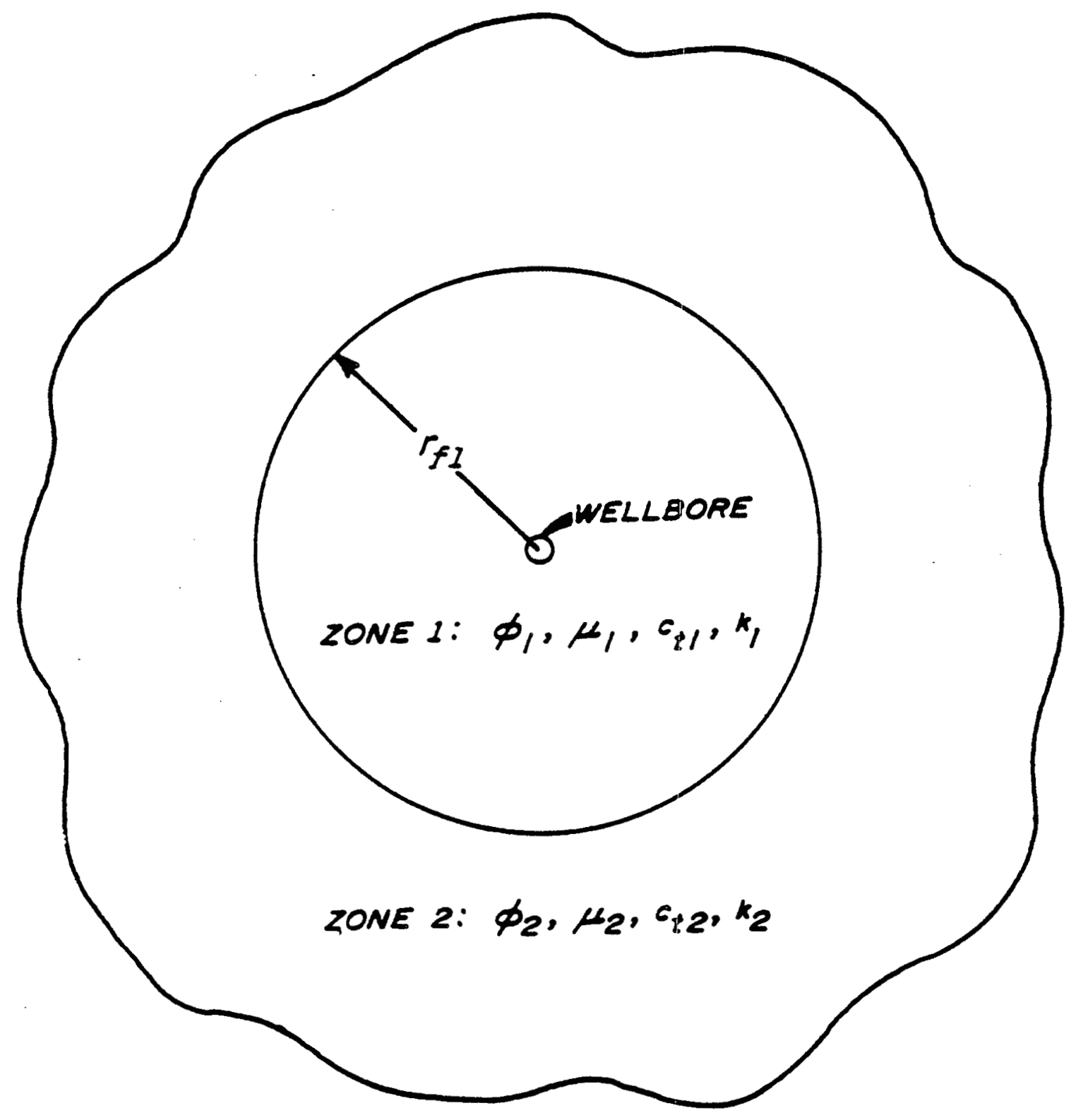

Figure 4. Schematic of composite reservoir model (from Earlougher, 1977). 
and the radius of discontinuity of the formation properties $\left(r_{f 1}\right)$. The analysis we have initiated involves iteration of the formation parameters occurring in the semi-analytical solution for the composite reservoir until the set of parameters that provides the best approximation to the data for the given bottomhole test is obtained. Table 1 shows preliminary results for the case of no reservoir boundaries (Figure 4). Figure 5 illustrates the fits to the bottomhole data obtained for the 1983 Reservoir Limits Test.

Table 1. Preliminary estimates of composite reservoir model parameters.

\begin{tabular}{|l|c|c|c|c|c|c|}
\hline & RLT & $79-\mathrm{hr}$ & $92-\mathrm{hr}$ & MRT & LTT & DIAG \\
$(10 / 83)$ & $(4 / 85)$ & $(1 / 86)$ & $(10 / 87)$ & $(87-91)$ & $(10 / 91)$ \\
\hline$\gamma \times 10^{2}$ & 9.63 & 19.14 & 18.71 & 19.72 & & 8.91 \\
$\delta \times 10^{2}$ & 2.25 & 5.05 & 4.93 & 4.84 & & 3.19 \\
$r_{f 1}(\mathrm{~m})$ & 601.8 & 588.6 & 588.6 & 588.3 & & 580.6 \\
\hline
\end{tabular}

The preliminary results are encouraging in that the solution method converges to consistent values for the reservoir parameters for the short-term bottomhole tests conducted during 1985 (79-hr), 1986 (92-hr) and 1987 (MRT). No solution is shown in Table 1 for the long-term pressure buildup test (LLT) since inclusion of boundaries is required. Furthermore, the inclusion of boundary effects is also required to better match the late time portions of the drawdown and buildup portions of the RLT (Figure 5). The data for the Diagnostic Test is noisy (Figure 3 ) and we plan to filter the data before further analysis.

It should be emphasized that no formation rock properties or reservoir boundary locations are assumed in this analysis procedure. It is an inversion method whereas the simulation model in the Appendix is forward modeling procedure. The two methods are complementary.

\section{Future Plans}

During FY1992 we plan to continue with our iterative calculational procedure to arrive at sets of reservoir parameters which best fit each of the bottomhole pressure transient tests. Inclusion of linear boundaries in the model will allow better fits to the RLT and LTT data and might allow estimation of reservoir volume. Comparison of the reservoir parameter sets corresponding to tests at different stages of the test history of the Gladys McCall well should help to isolate the cause of the changes in the apparent value of kh and to determine if it is related to nonlinear rock response. These results and any new insight obtained from the planned pressure measurements in Sands 2 and 4 will be used to better understand the Gladys McCall reservoir behavior. 


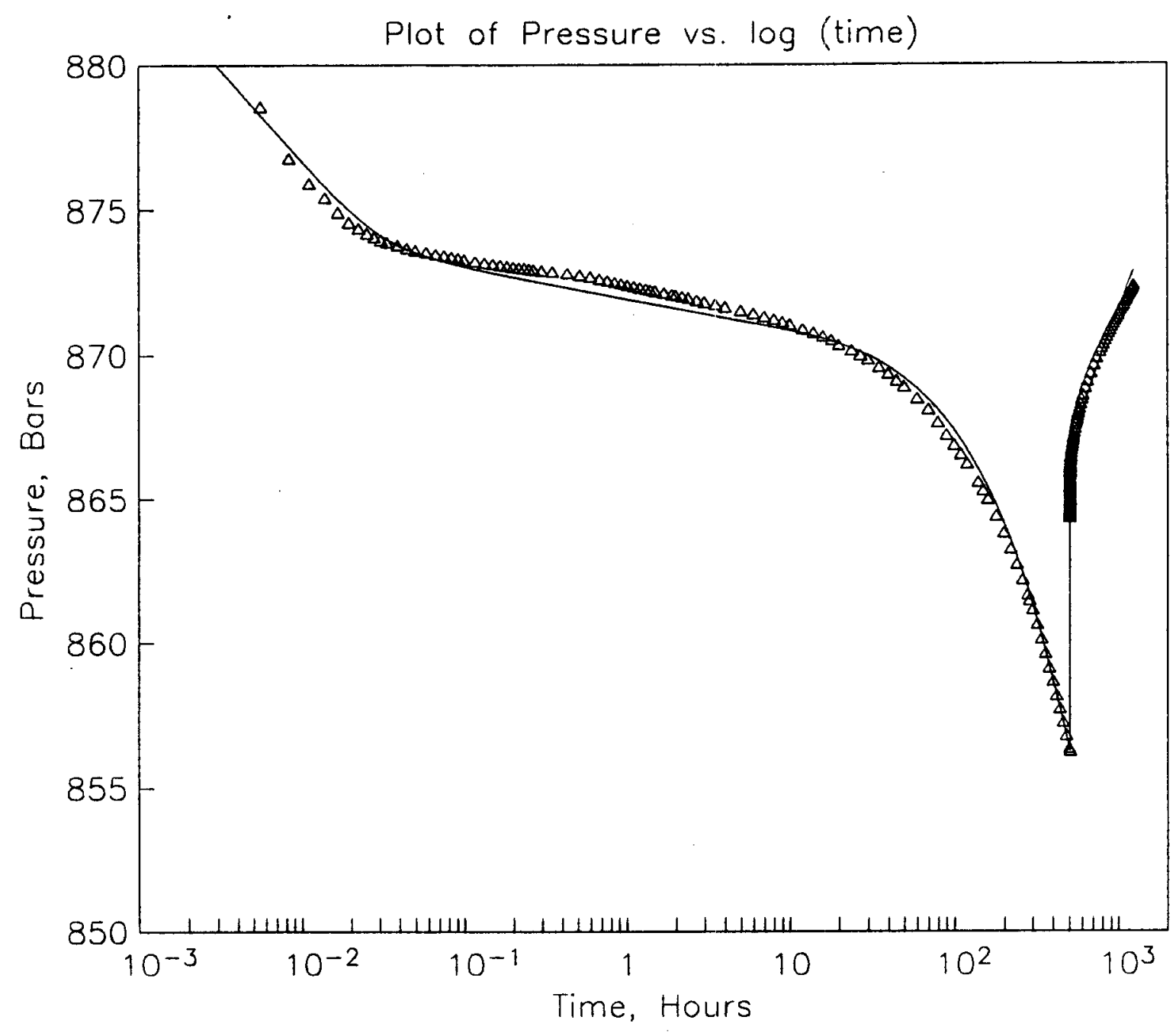

Figure 5. Comparison of preliminary fit of composite reservoir model (curve) to RLT pressure transient data (points). Datum level is 15,100 feet. 


\section{References}

Earlougher, R. C., Jr. (1977), “Advances in Well Test Analysis”, Monograph No. 5, Society of Petroleum Engineering of AIME, Dallas, Texas.

Riney, T. D. (1991), "Depletion and Recovery Behavior of the Gladys McCall GeopressuredGeothermal Reservoir", Energy Sources Journal, Vol. 13, pp. $483-503$ (OctoberDecember).

Randolph, P. L., S. Wohadlo and S. Foh (1991), "Gladys McCall Well Activity Report for October, 1991". 


\title{
Depletion and Recovery Behavior of the Gladys McCall Geopressured Geothermal Reservoir
}

\author{
T. D. RINEY \\ S-CUBED \\ La Jolla, California 92038-1620
}

\begin{abstract}
Many sedimentary basins throughout the world contain sealed fault blocks in which the pore fluids are at higher pressures and temperatures than normal as a consequence of their depositional environment. The U.S. Department of Energy has drilled, completed, and tested four deep research wells in selected geopressured geothermal prospects in the Texas-Louisiana Gulf Coast region to evaluate the recoverability of the thermal, hydraulic, and chemical (methane) energy in this potential energy resource. The wells are expensive and the specific energy of the fluids is relatively small, but the total recoverable energy from a single well can be extremely large. Long-term testing of the Gladys McCall No. 1 research well, located in Cameron Parish, Louisiana, U.S.A., has defined an impressively large geopressured geothermal reservoir. An integrated analysis of the test data is presented, and a numerical model is constructed that matches the available data for the 6.5-year test history of the well.
\end{abstract}

Keywords geothermal energy, geopressured resource, reservoir engineering

\section{Introduction}

Many sedimentary basins contain formations with pore fluids at higher than hydrostatic pressures (vertical fluid-pressure gradients greater than about $0.465 \mathrm{psi} / \mathrm{ft}$ ); these formations are called geopressured. The geopressured strata are comprised of undercompacted clays (or shales) and sandstones with the interstitial fluids bearing most of the overburned pressure. The pore pressure is generally well in excess of hydrostatic, and the fluids are saline, hot, and contain dissolved methane. Thus, the fluid contains energy in three forms; thermal energy, hydraulic (or pressure) energy, and chemical energy associated with the methane.

Among geopressured basins in the United States, the northern Gulf of Mexico basin has been most extensively investigated. A review of the estimates of the energy recoverable from the Gulf Coast region has been presented by Garg, Riney, and Wallace (1985). As part of its program to define the magnitude and recoverability of the geopressuredgeothermal energy resource, the U.S. Department of Energy (DOE) has drilled and tested four deep research wells in the Texas-Louisiana Gulf Coast region:

(1) Pleasant Bayou Well No. 2, Brazoria County, Texas.

(2) Amoco Fee Well No. 1, Sweet Lake Field, Cameron Parish, Louisiana.

(3) L. R. Sweezy Well No. 1, Parcperdue Field, Vermilion Parish, Louisiana.

(4) Gladys McCall Well No. 1, Cameron Parish, Louisiana.

Testing of the Amoco Fee and L. R. Sweezy wells has been completed, and the wells have been plugged and abandoned. Long-term production testing of the Pleasant Bayou 
well is still in progress. Reservoir pressure recovery is currently (May 1990) being monitored in the Gladys McCall well following long-term production testing of the well.

One of the objectives of the DOE program is to investigate the pressure maintenance mechanisms that operate within the reservoirs tested by the design wells. The Parcperdue reservoir was selected because of its well-defined geology and volume so that the testing could be completed within one year. Depletion testing had to be terminated, however, when excessive sand was produced from the unconsolidated formation. The Amoco Fee well exhibited a much larger than anticipated pressure-drawdown during short-term flow testing. Analysis of the downhole pressure data indicated that the well penetrated a zone of relatively high permeability but flow was constrained by either low permeability or geologic structure away from the well.

Selection of the Pleasant Bayou and the Gladys McCall well sites was based on research at the University of Texas at Austin and Louisiana State University that identified localized regions where thick, high-pressure, high-temperature sandstone masses existed as a result of isolation by growth faults, salt movement, facies boundaries, or other factors. These geologic studies (Bebout, Loucks, and Gregory 1978; Bebout 1982; Brunheld 1984) successfully identified the Pleasant Bayou and Gladys McCall prospects as large volume aquifers that could be produced for extended periods at high flow rates.

The Gladys McCall geopressured prospect lies at the western edge of the Rockefeller Wildlife Refuge about 55 miles southeast of Lake Charles in Cameron Parish, Louisiana. Preliminary studies of the geology and structure of the area were conducted by $D$. G. Bebout (1982) and Brunheld (1984) based on well logs from the subject well and five nearby deep wells. The approximate locations of the three major growth faults considered to control the structure of the prospect are shown at 15,500 feet in Figure 1; the east-west length of the fault block could not be determined from available information.

Recently, John (1988) reviewed the geology of the Gladys McCall prospect. Although no new geological information was available to better establish reservoir boundaries, production flow testing had established that the Gladys McCall test was drawing from a large reservoir. John's model for the depositional origin of the geopressured sand section penetrated by the Gladys McCall test well considers the entire section to be a genetic unit generated within the same channel system, consisting of interconnected channel and point bar sandstones deposited through time. When the sand supply was interrupted, shale may have been deposited locally, but the laterally extensive channel and point bar sands may still be interconnected within the genetic system. Consequently, John (1988) suggests that the whole thickness of the sand section, though appearing on the electric log as possibly different and separated sandstones, may behave as a single sand body, allowing fluid communication at shale breaks during brine production.

\section{Gladys McCall Test Data}

Gladys McCall Well No. 1 was spudded on May 27, 1981, drilled to a total depth of $16,510 \mathrm{ft}$, and plugged back to $15,831 \mathrm{ft}$. A 7 -in. diameter casing string was cemented from the surface to $15,958 \mathrm{ft}$, and the well was completed with 5-in. diameter production tubing. Technadril-Fenix and Scisson (1982) managed the drilling, completion, and testing of the well until October 1985; Eaton Operating Company took over management of the well for DOE at that time. The stratigraphic section seen in the borehole consists of alternating massive sandstones and thin shales. There are approximately $1150 \mathrm{ft}$ net of sand in the target Miocene sand within the $14,412 \mathrm{ft}$ to $16,320 \mathrm{ft}$ interval penetrated by the test well. Eleven sequentially number sand zones separated by shale breaks at the 


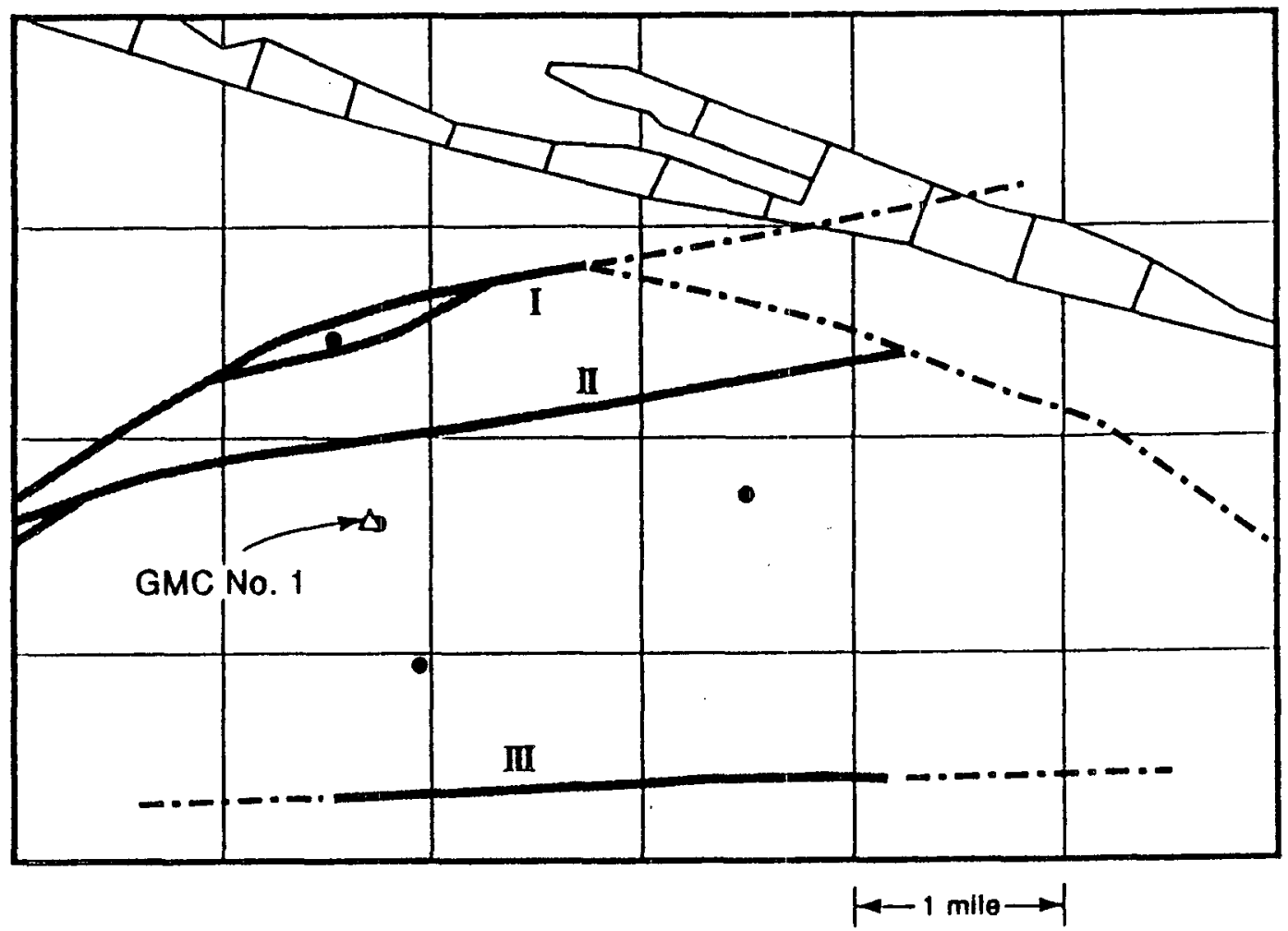

Figure 1. Major growth faults within lower Miocene section at depth (15,500 feet) between sand zones 8 and 9 with locations of Gladys McCall No. 1 and nearby deep wells. Geologic map adapted from Technadril-Fenix and Scisson (1982).

wellbore were identified from log analysis by Technadril-Fenix and Scisson (1982). Over two-thirds of the net sand is contained in three of the eleven sand zones (nos. 2, 8, and 9). Only sands 8 and 9 have been perforated.

Sand zone 9, from $15,508 \mathrm{ft}$ to $15,636 \mathrm{ft}$, was flowed from March 21,1983 , to April 14, 1983. After gas separation, the brine produced was injected into a nearby disposal well. A Panex downhole pressure/temperature gauge positioned at $15,460 \mathrm{ft}$ recorded the pretest reservoir pressure of 12,911 psia and temperature of $298^{\circ} \mathrm{F}$. Because of the rapid pressure drawdown in the well, sand zone 9 was sealed off with a plug set at $\sim 15,500 \mathrm{ft}$ in preparation for testing sand zone 8 .

The 7-in. casing was perforated to test sand zone 8 , from $15,158 \mathrm{ft}$ to $15,490 \mathrm{ft}$ (sand thickness $h=332 \mathrm{ft}$ ). A Panex pressure/temperature gauge was fixed at a depth of $15,100 \mathrm{ft}$ to record the initial pressure and temperature: $P_{i}=12,784 \mathrm{psia}$ and $T_{i}=289.2^{\circ} \mathrm{F}$. Production started on October 7,1983 , and the test well produced over $27.3 \times 10^{6} \mathrm{sep}$ bbl of brine (measured at the brine/gas separator conditions) from October 7, $1983(t=0)$ through October $29,1987(t=1483$ days $)$ when the well was shut in for a long-term pressure build up test still underway (May 1990). The produced fluid was remarkably free of sand and fines over its entire production history.

Laboratory tests (Kelkar et al., 1982) under bench conditions on well-consolidated core samples from the test well gave average values for porosity and permeability of $\phi \sim 0.168$ and $k \sim 83$ md, respectively. Under simulated reservoir conditions they reported permeabilities ( $k-1$ to $17 \mathrm{md}$ ) that are much smaller than implied by actual 
field measurements at the test well $(k \sim 133 \mathrm{md})$. Kelkar et al. also reported values for the uniaxial compaction coefficient $\left(C_{m}-2 \times 10^{-7} \mathrm{psi}^{-1}\right)$ that are very low and inconsistent with values $\left(C_{m}-8 \times 10^{-7} \mathrm{psi}^{-1}\right)$ deduced from their measurements for bulk compressibility and Poisson's ratio. The corresponding values for the total formation compressibility would be $C_{T}=4.0 \times 10^{-6} \mathrm{psi}^{-1}$ and $C_{T}=7.7 \times 10^{-6} \mathrm{psi}^{-1} . \mathrm{Be}-$ cause of these ambiguities, we will use a value of $C_{T}=6.27 \times 10^{-6} \mathrm{psi}^{-1}$ based on correlations for consolidated sandstone (Earlougher 1977).

Studies by the Rice University brine research group showed that fluids produced from sand zones 8 and 9 are essentially identical. Weatherly Laboratories, Inc. reported the following properties of fluid samples recombined to approximate reservoir conditions (sand zone 8): brine compressibility $C_{w} \sim 2.76 \times 10^{-6} \mathrm{psi}^{-1}$, dynamic viscosity $\mu \sim 0.31 \mathrm{cp}$, and bubble pressure $\sim 9200 \mathrm{psia}$. The average gas-to-water ratio for the total gas production from the test well is GWR $\sim 30.15$ SCF/STB $\left(\mathrm{ft}^{3} \mathrm{bbl}^{-1}\right.$ at 14.67 psia, $60.33^{\circ} \mathrm{F}$ ). Average salinity of the brine is $-97,800 \mathrm{mg} / \mathrm{l}$.

Although production from sand zone no. 8 by Gladys McCall Well No. 1 included numerous rate changes since initiation of the Reservoir Limits Test (RLT) on October 7 , $1983(t=0)$, the production history may be divided into two major phases. Except for relatively short time intervals (following decreases in the flow rate), the bottomhole pressure generally decreased from the time the RLT was initiated up to April 21, 1987 $(t=1292$ days). This period of over 3.5 years will be called the depletion phase of the reservoir response. The flow rate during the depletion phase was over $30,000 \mathrm{sep} \mathrm{b} / \mathrm{d}$ part of the time and averaged $\sim 19,600$ sep b/d.

Starting on April 21, 1987, the flow rate of the well was lowered in four steps over a four-week period and then held at $q \sim 9800 \mathrm{sep} b / \mathrm{d}$ until the initiation of the multirate flowing portion of the Long Term Test (LTT) on October 24, 1987. The well was shut on October $29(t=1483$ days $)$ in order to monitor the pressure recovery during the buildup portion of the LTT. The pressure generally increased during the 191-day period of reduced flow rate $(\sim 10,040$ sep b/d from April 21 to October 29, 1987) and has continued to increase since shut in. This total period of about 3.0 years from April 21, 1987, to the present will be called the recovery phase of the reservoir response.

An earlier article (Riney 1988) presented an analysis of the test data available at the end of the depletion phase. A conceptual model of the reservoir was constructed that depends on cross-flow at shale breaks from sands overlying sand zone 8 for the observed pressure maintenance, and a reservoir simulation model based on the cross-flow concept was developed. The present article presents analysis of the more complete data now available. This includes reanalysis of the depletion phase data in conjunction with the analysis of the new data from the recovery phase of the testing of the Gladys McCall Well No. 1. Modification of the reservoir simulation model described in the earlier article is necessary to provide a satisfactory match to the integrated data sets comprised of both the depletion and recovery phases of the test history.

\section{Method of Analysis}

The data analysis is complicated by the fact that the well initially experienced severe calcite scaling within the production tubing. Costly and time consuming acid treatments were employed on four occasions to remove the scale. Control of scaling of the well tubulars was then attempted by injecting into the formation a chemicai mixture (mostly phosphonate) designed to inhibit the precipitation of calcium carbonate from the brine. The first attempt to inject the phosphonate "pill" into sand zone 8 in November 1984 
$(t-418$ days) was aborted when the incremental injection pressure exceeded 600 psi. The pill flowback contained solid precipitates, and formation plugging was suspected at the time (Durrett 1985). This appeared to be confirmed when it was not possible to lower the test tool below 15,158 feet when the well was next logged on April 13, 1985. The second attempt to inject a scale inhibitor pill in May $1985(t \sim 594$ days) was also aborted. Successful pill injections were accomplished during June 1985 ( $t \sim 628$ days) and February $1986(t-851$ days). The success of the scale inhibitor pills has been crucial to the success of the geopressured test well program (Tomson, Matty, and Durrett 1985). Analysis of the Gladys McCall production data has revealed, however, that even successful injections cause an increase in the apparent skin factor, causing an increase in the near-wellbore pressure loss (Riney 1988).

There have been four periods during the 6.5 years of sand zone 8 test history when downhole pressure transient tests have been performed:

(1) October 1983 to December 1983; reservoir limits test (drawdown/buildup)

(2) April 1985; 79-hr test (buildup only)

(3) January 1986; 92 -hr test (buildup only)

(4) October 1987 to present; long-term test (drawdown/buildup).

The first three tests were conducted during the depletion phase, and the results were described by Riney (1988). The LTT is composed of measurements that were continuously recorded over a multi-rate drawdown and early buildup portion of the test, augmented by measurements made while logging downhole pressure/temperature values, at increasingly longer time intervals between logs, from November 1987 to the present.

Both the 79-hr and 92-hr tests were found to infer a near-well transmissivity (kh) equal to about half the value measured during the original RLT (Riney 1988). This reduction in transmissivities was attributed to the presumed plugging of about half the thickness in sand zone 8 in combination with a shale stringer (vertical flow barrier) identified from well logs at $15,365 \mathrm{ft}$ to $15,369 \mathrm{ft}$ (Fig. 2). At the time of the $92-\mathrm{hr}$

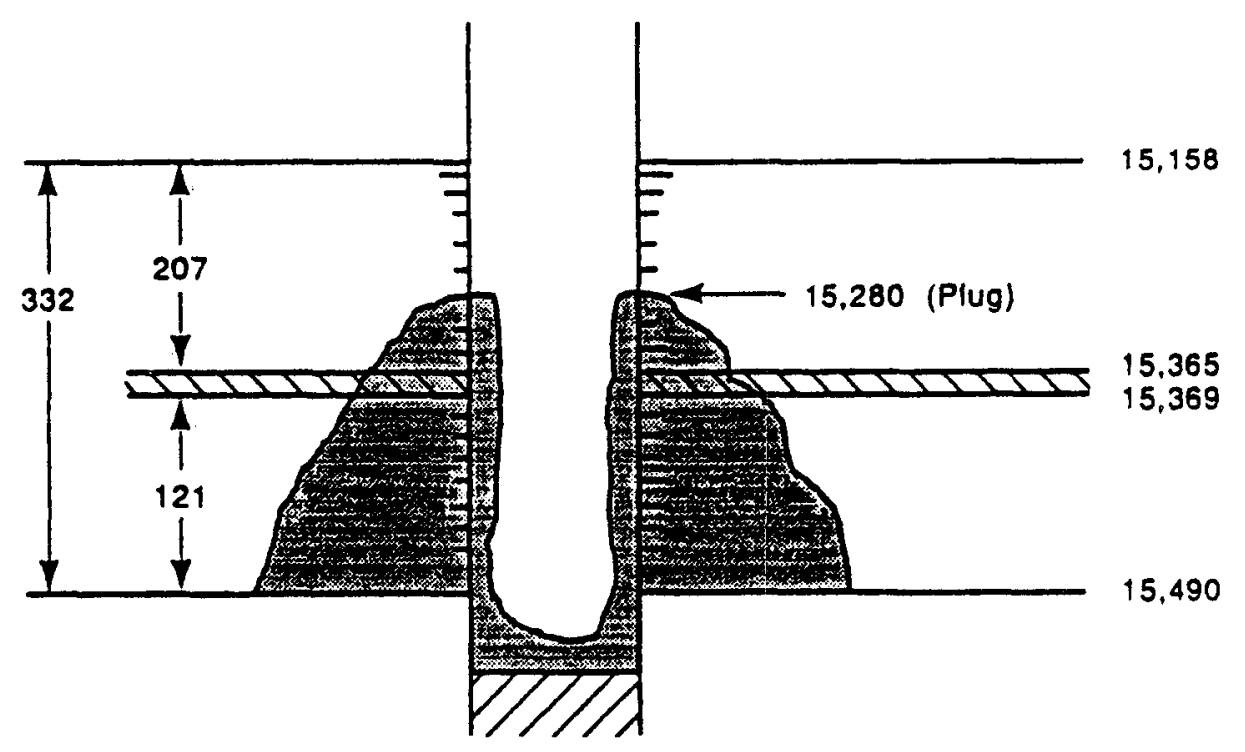

Figure 2. Schematic showing location of the shale stinger in sand zone 8 and depth in feet of presumed plug reported at time of 79 -hr test. 
test, however, the well was again logged and the tool reached wellbottom without detecting any obstruction. It was hypothesized that the plugging within the formation remains since there is no flow below the shale stringer to flush the precipitates from the pores. Parametric reservoir simulation studies were performed to estimate the effective distance $(\ell)$ that the shale stringer extends laterally from the wellbore. It was found that a vertical flow barrier for a distance $\ell \sim 657 \mathrm{ft}(200 \mathrm{~m})$ provided a good match to the downhole pressure transient data recorded before and after the presumed plugging (Riney 1988).

In preparation for the LTT, a Panex pressure/temperature gauge was lowered in Gladys McCall Well No. 1 on October 24, 1987 ( $t$ - 1478 days) and set at a depth of $14,650 \mathrm{ft}$ with the well producing brine at $\sim 9950 \mathrm{sep} b / \mathrm{d}$. At 01:17:00 on October 25, the flow rate was increased to $-15,050 \mathrm{sep}$ b/d. At 13:58:40 on October 25 the rate was decreased to $\sim 12,440 \mathrm{sep} b / \mathrm{d}$, and at 20:05:30 on October 25 the rate was lowered to $\sim 9950 \mathrm{sep} b / \mathrm{d}$. On October 26 it became apparent that the measured downhole pressure values were drifting with time. The original ("old") downhole Panex gauge was pulled out and a "new" Panex pressure/temperature was set at 14,650 feet at 22:00:00 on October 26. The flow continued at $\sim 9950 \mathrm{sep} b / \mathrm{d}$ until the well was shut in at 20:02:10 on October 29, $1987(t=35,598.8 \mathrm{~h})$. The buildup pressure was monitored continuously until 07:00:00 on November 5, 1987, when the new gauge was pulled. The subsequent pressure recovery has been monitored by isolated bottomhole pressure and temperature measurements made with increasing time intervals between logs.

Detailed analysis of the LTT pressure data revealed a drift of $3.62 \mathrm{psi} / \mathrm{hr}$ in the recordings of the old gauge. For analysis purposes the LTT data were further corrected to the depth of 15,100 feet at which measurements were made in the three previous bottomhole tests. The corrected old gauge data points are plotted with the new gauge data in Figure 3. The discontinuity reflects errors in the corrections for the old gauge data in some combination with differences in the calibrations and downhole positioning of the two gauges.

Except for these four bottomhole pressure transient tests, the Gladys McCall reservoir response must necessarily be inferred from wellhead recordings. The wellhead pressure measurements are related to the reservoir response as follows.

$$
p W H=p B H-\Delta p_{w b}=p_{i}-\Delta p_{\text {res }}-\Delta p_{s k}-\Delta p_{w b}
$$

Here the pressure drop in the wellbore (i.e., within the production string) is the sum of frictional and hydrostatic pressure losses $\left(\Delta p_{w b}-\Delta p_{\text {fric }}+\Delta p_{\text {hydr }}\right) ; p_{i}$ is the initial reservoir pressure, $\Delta p_{\text {res }}$ the pressure drop in the reservoir in the absence of a skin effect $(s=0)$, and $\Delta p_{s k}$ the pressure drop due to the skin effect $(s>0)$. Relating the wellhead measurements to the characteristics of the geopressured reservoir involves calculations for subsurface pressure losses $\left(\Delta p_{\text {wb }}, \Delta p_{s k}, \Delta p_{\text {res }}\right)$.

During the evaluation of the total available data set from Gladys McCall Well No. 1 we have

(1) Performed simultaneous analysis of the pressure transient data from the four isolated downhole tests. The revised values for the near-well formation properties are used in reservoir simulation computations to calculate $\Delta p_{\text {res: }}$

(2) Evaluated the wellhead pressure data available just prior to and immediately after planned shut in periods during the depletion phase to estimate $\Delta p_{s k}$.

(3) Recalibrated the wellbore flow model to improve the calculations for $\Delta p_{w b}$ and, 


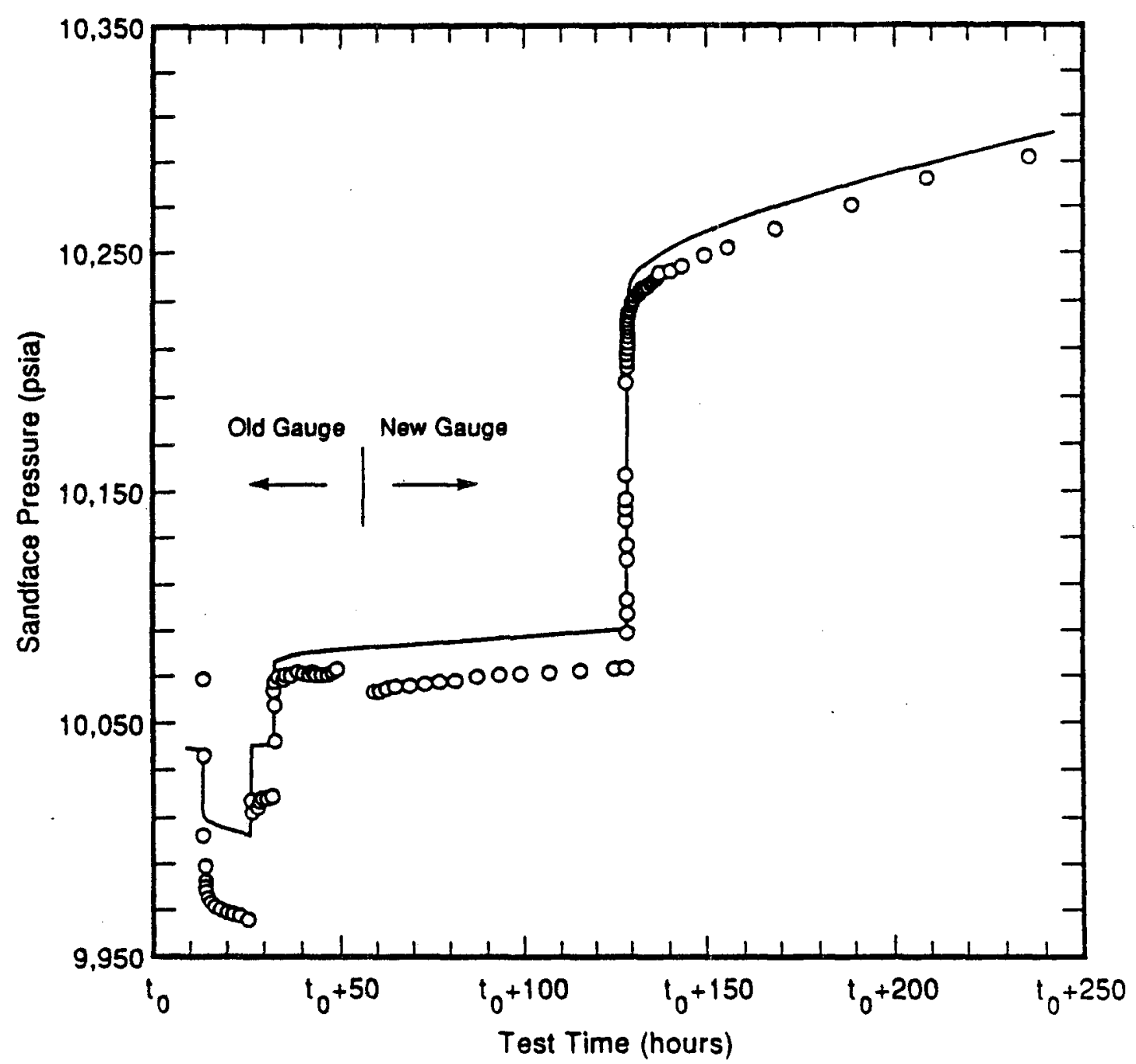

Figure 3. Data points are for LTT bottomhole measurements corrected to 15,100 feet. Old gauge data also corrected for drift. Curve is the simulated history. Test time referenced to $t_{0}-35,470 \mathrm{hr}$ (on October 25 . 1987).

consequently, improve earlier estimates to bottomhole pressures during the depletion phase.

These results will be described in the following sections.

\section{Simultaneous Analysis of Pressure Test Data}

The reservoir analysis is simplified by the relatively low gas content. Preliminary parametric simulations were made that maximized the credible effects of any free gas that might evolve within the formation under Gladys McCall conditions; the studies show that the gas in the formation would be confined to a very small zone at the sandface. Parametric simulations assessing the effects of irreversible rock compaction and stressdependent permeability were also conducted (Riney 1986). These simulations indicated that any associated nonlinear effects at Gladys McCall would likely occur only in the neighborhood of the wellbore. Such local effects would be reflected as variations in the apparent value of the skin factors when using linear methods of analysis. 
Consider a well with radius $r_{w}$ flowing under semi-steady state conditions at rate $q$ for an equivalent production period $t_{p}$. If there is a step rate change $(\Delta q)$ at time $t_{p}$, the associated sandface pressure change at time $t_{p}+\Delta t\left(\Delta p-p w_{1 t p+\Delta t}-p w_{1 p p}\right)$ is approximated by (in oilfield units; see Earlougher 1977)

$$
\frac{\Delta p}{\Delta q}=m^{\prime}\left(\log \Delta t+\log \frac{k}{\phi \mu C_{T} r_{w}^{2}}-3.23+0.87 s\right)
$$

where $m^{\prime}=162.6 \mu B / k h$. The formation factor $(B)$ is required to convert separator barrels to reservoir barrels. If we assume the fluid viscosity $(\mu)$, formation porosity $(\phi)$, and total compressibility $\left(C_{T}\right)$ are known, a semi-logarithmic plot of pressure transient data can be used to estimate the values of transmissivity $(k h)$ and skin factor $(s)$. The slope $m^{\prime}$ yields $k h$ and the intercept at $\Delta t=1 \mathrm{hr}$ yields $s$,

$$
s=1.151\left\{\frac{1}{m^{\prime}}\left[\frac{\Delta p}{\Delta q}\right]_{\mathrm{Ihr}}-\log \frac{k}{\phi \mu C_{T} r_{w}^{2}}+3.23\right\}
$$

Figure 4 compares plots of $\Delta p / \Delta q$ versus $\log \Delta t$ for the 79-hr (April 9-12, 1985) and 92-hr (January 23-27), 1986) buildup tests with plots for two steps of the LTT (October 24, 1987-present). The plot for the first step (rate change from 9950 to 15,050 sep b/d) of the multi-rate drawdown portion of the LTT is closely approximated by a line of the same slope $\left(m^{\prime}=1.75 \times 10^{-3} \mathrm{psi} / \mathrm{sep} \mathrm{b} / \mathrm{d}\right)$ as lines approximating the 79-h and 92-h tests. The rate was maintained at $15,050 \mathrm{sep} \mathrm{b/d}$ for $12.68 \mathrm{~h}$. The next two step-rate changes did not provide useful data for analysis because of the short time (step 2) and a gauge failure (step 3). The plot for the fourth step, the early part of the buildup portion of the LTT (started on October 29, 1987), is also closely approximated by a line of the same slope $\left(m^{\prime}=1.75 \times 10^{-3} \mathrm{psi} / \mathrm{sep} \mathrm{b} / \mathrm{d}\right)$. The slow rise times for the two portions of the LTT shown in Figure 4 appear to be associated with the time taken to complete the flow-rate changes.

Analogous plots for the drawdown (October 7-28, 1983) and buildup (October 28November 30,1983 ) portions of the RLT show that both early time semilog plots are approximated by straight lines of slope $m^{\prime}=1.13 \times 10^{-3} \mathrm{psi} / \mathrm{sep} \mathrm{b} / \mathrm{d}$.

In the previous simultaneous analysis, the same values for the input parameters were employed as were used in the separate analyses made at the time of each of the downhole pressure transient tests (Riney 1988): $r_{w}=0.2917 \mathrm{ft}, h=332 \mathrm{ft}, \phi=0.16, \mu=0.31$ $\mathrm{cp}, C_{T}=6.27 \times 10^{-6}, B=0.984$. The flow rate changes, and the flowing pressures (at $15,100 \mathrm{ft}$ ) just prior to the rate changes are listed in Table 1. The values for the formation transmissivity $(k h)$ calculated from the slopes $\left(m^{\prime}\right)$ in the semilog plots are also listed. The drawdown and buildup portions of the initial RLT imply a transmissivity of $\sim 44,090 \mathrm{md}-\mathrm{ft}$; all subsequent pressure transient tests imply a transmissivity of $\sim 28,340 \mathrm{md}-\mathrm{ft}$. Assuming $h=332 \mathrm{ft}$, the pressure transient data taken without further information would imply a reduction in near-well permeability form an initial value of $k=133 \mathrm{md}$ to $k=85 \mathrm{md}$.

Table 1 also lists the values of $[\Delta p / \Delta q]_{\text {thr }}$ read from the straight line approximations to the semilog plots (e.g., Fig. 4). Equation 3 yields the corresponding estimates for the skin factor $(s)$ at the time of each of the six downhole pressure transient tests. The estimate for the drawdown portion of the LTT is enclosed in parentheses in Table 1, since any vertical displacement of the $\Delta p / \Delta q$ curve (Fig. 4) that might be present after correcting for the linear drift in the old gauge pressure values would affect the estimate for $s$. 


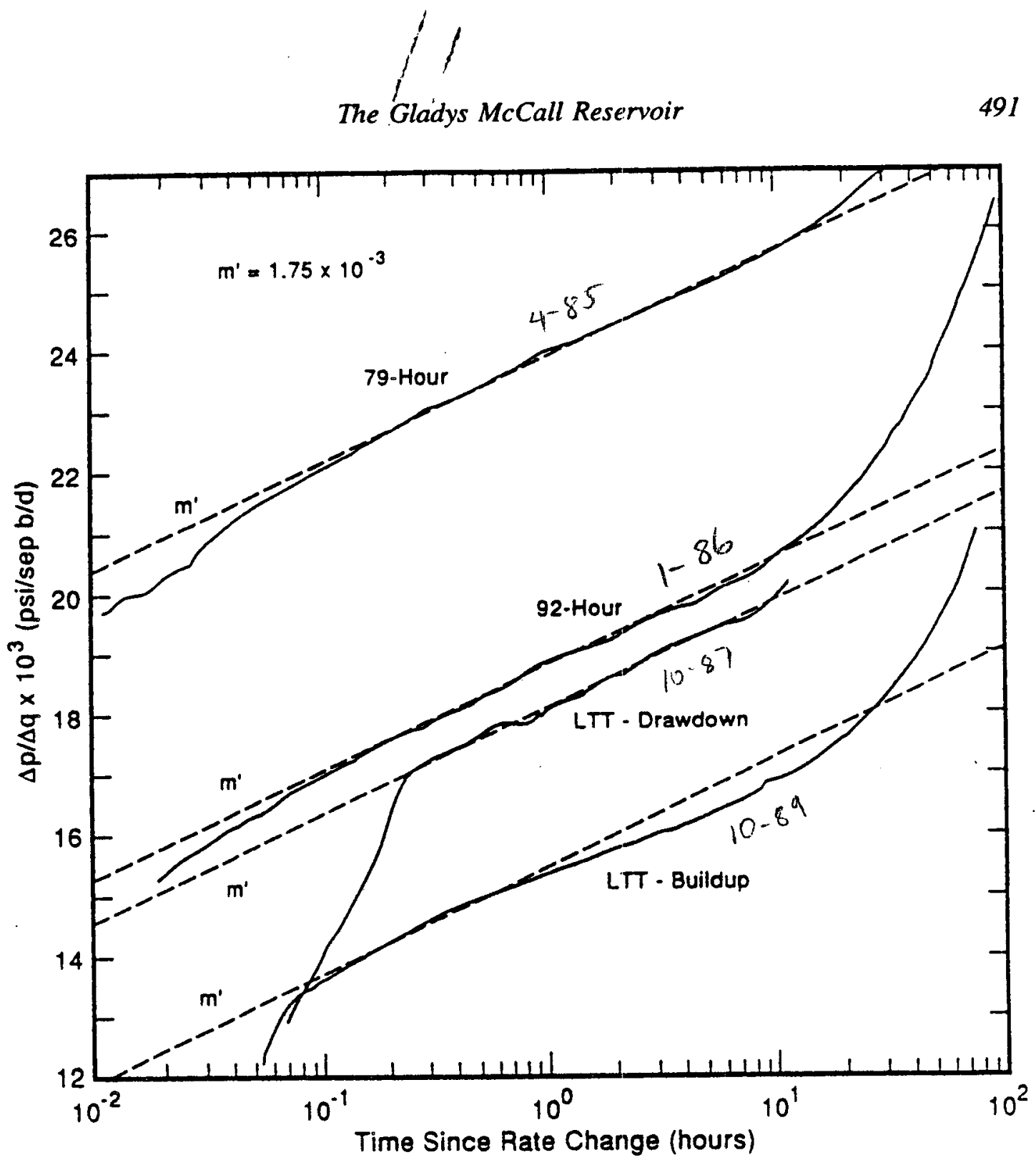

Figure 4. Bottomhole pressure transient data from 79-hr buildup test, 92 -hr buildup test, one step of the LTT multi-rate drawdown, and the early portion of the LTT buildup. Datum level is $15,100 \mathrm{ft}$.

From Equations 2 we see that the pressure drop due to the skin effect changes with $\Delta q$ according to $\delta p_{s}=m^{\prime}(0.87 s) \delta q$, or

$$
\delta p_{s}=\frac{141.2 \delta q \mu B}{k h} s
$$

We note that the discrepancy between the skin factor estimates for the two steps of the LTT $(\delta s=4.68-2.97=1.71)$ would correspond to a constant error in the corrected old gauge pressure values of

$$
\delta p_{o}<\frac{141.2(5100)(0.31)(0.984)(1.71)}{28,340} \sim 13 \mathrm{psi}
$$

Since an error of this size is possible in our correction for the drift in the pressure values 
Table 1

Summary of Results of Simultaneous Analysis of Bottomhole Pressure Transient Measurements for Gladys McCall Sand Zone 8. Long-Term Test Measurements at 14,650 Feet Were Corrected to a Common 15,100 Feet Datum Level

\begin{tabular}{|c|c|c|c|c|c|c|}
\hline & \multicolumn{2}{|c|}{ Reservoir Limits Test } & \multirow[b]{2}{*}{ 79-Hour Buildup } & \multirow[b]{2}{*}{ 92-Hour Buildup } & \multicolumn{2}{|c|}{ Long-Term Test } \\
\hline & Drawdown & Buildup & & & Drawdown & Buildup \\
\hline Date of measurement & Oct $07, ' 83$ & Oct $28,{ }^{\prime} 83$ & April 09, '85 & Jạn 23, '86 & Oct $25, ' 87$ & Oct $29, ' 89$ \\
\hline Test days, $\mathrm{d}$ & 0 & 21 & 550 & 839 & 1,479 & 1,483 \\
\hline$Q, 10^{3}$ sep b & 0 & 298 & 7,788 & 13,951 & 27,131 & 27,182 \\
\hline$\left[p_{w f}\right]_{0-}$, psia & 12,784 & 12,418 & 10,855 & 10,267 & 10.068 & 10,074 \\
\hline$\Delta q$, sep $b / d$ & 14,162 & 14,162 & 15,438 & 10,470 & 5,100 & 9,950 \\
\hline$[\Delta p / \Delta q]_{\mathrm{hhr}} \times 10^{3}, \mathrm{psi} / \mathrm{sep} \mathrm{b} / \mathrm{d}$ & 9.55 & 9.78 & 23.9 & 18.8 & 18.1 & 15.5 \\
\hline$m^{\prime} \times 10^{3}, \mathrm{psi} / \sim /(\operatorname{sep~b/d})$ & 1.13 & 1.13 & 1.75 & 1.75 & 1.75 & 1.75 \\
\hline$k h$, md-ft & 44,090 & 44,090 & 28,340 & 28,340 & 28,340 & 28,340 \\
\hline$s$ & 2.28 & 2.51 & 8.49 & 5.11 & $(4.68)$ & 2.97 \\
\hline
\end{tabular}


measured with the old gauge, the skin factor based on the early buildup data $(s=2.97)$ is the preferred estimate at the time of the LTT.

\section{Evaluation of Skin Factor Variations}

There have been numerous times during the depletion testing of Gladys McCall Well No. 1 when the production tubing was free of scaling and the well had flowed at a constant rate for a sustained period prior to a planned shut in. On 21 occasions recordings of the wellhead pressure were made on a continuous basis just prior to and immediately after shut in. These data can be evaluated to estimate $\Delta p_{s k}$ (and thus the apparent value of $s$ ) at those times. For this purpose we set $\Delta t=3 \mathrm{~m}=0.05 \mathrm{hr}$ in Equation 2 and solve for $s$ to obtain

$$
s=1.151\left\{\frac{1}{m^{\prime}}\left[\frac{\Delta p}{\Delta q}\right]_{3 \mathrm{~m}}-\log \frac{k(0.05)}{\phi \mu C_{T} r_{w}^{2}}+3.23\right\}
$$

The choice of $\Delta t=3 \mathrm{~m}$ is made since it has been found to be long enough for wellbore storage effects to be small, and short enough for thermal changes to be negligible.

When the well is shut, $\Delta p_{w b} \rightarrow \Delta p_{\text {hydr }}$ The values of $\Delta p_{\text {hydr }}$ have been estimated (at the 15,100-ft datum level) from simultaneous wellhead and bottomhole P/T measurements made at the times of the RLT and 79-hr shut-in tests. The sandface shut-in pressures $\left.p_{w s}\right]_{3 m}$ are calculated based on the approximation $\left.\left.p_{w s}\right]_{3 m}=p W H\right]_{3 m}+\Delta p_{h y d r}$. Estimates for the sandface flowing pressures just prior to shut-in are based in Equation $\left.1, p_{w f} \mathrm{l}_{\Delta t-0-}=p W H\right]_{\Delta t-0-}+\Delta p_{w b}$, with the values $\Delta p_{w b}$ calculated using the recalibrated model for wellbore flow (see next section).

Using Equation 5 with $r_{w}=0.2917 \mathrm{ft}, h-h^{\prime}=207 \mathrm{ft}$ (see Fig. 2), $\phi=0.16$, $\mu=0.31 \mathrm{cp}, C_{T}=6.2710^{-6} \mathrm{psi}^{-1}$, and the values calculated for $\left.\Delta p=p_{w s}\right]_{3 m}-$ $\left.p_{w f}\right]_{\Delta t-0-}$ (with $m^{\prime}=1.75_{x} 10^{-3} \mathrm{psi} / \mathrm{sep} \mathrm{b} / \mathrm{d}$ from Table 1 ), the estimates for the skin factor $(s)$ are obtained for the 21 shut-in times. The results are plotted in Figure 5 against the corresponding values of the bottomhole $(15,100$-ft datum level) pressure drop from the initial reservoir pressure of 12,784 psi. Also plotted are the estimates for $s$ given in Table 1 from the reevaluation of the downhole pressure transient test data.

The apparent skin factor values displayed in Figure 5 may be related to times at which scale inhibitor pills were injected.

October 1983 At the time of the original RLT the downhole measurement indicate a skin factor of $s=2.28$ to 2.5 .

November 1984 First aborted attempt to inject pill; plugging a part of formation thickness near wellbore by precipitates suspected. Large increase in $s$ value.

April 1985 At the time of the 79-hr buildup test, analysis of downhole measurements indicate a skin factor of $s=8.49$. Hypothesized skin decrease subsequent to November 1984 pill is indicated by dashed curve approaching the 79-h data point in Figure 5.

May 1985 Second aborted pill injection causes large increase in skin factor value. Analysis of surface pressure data indicates that the large value of $s$ subsequently decreases with continuous production; decrease attributed to partial flushing of precipitates from pores by flowing brine (see Riney 1988).

June 1985 First successful pill injection; analysis of surface pressures again indicates an associated large increase in apparent skin factor observed along with 


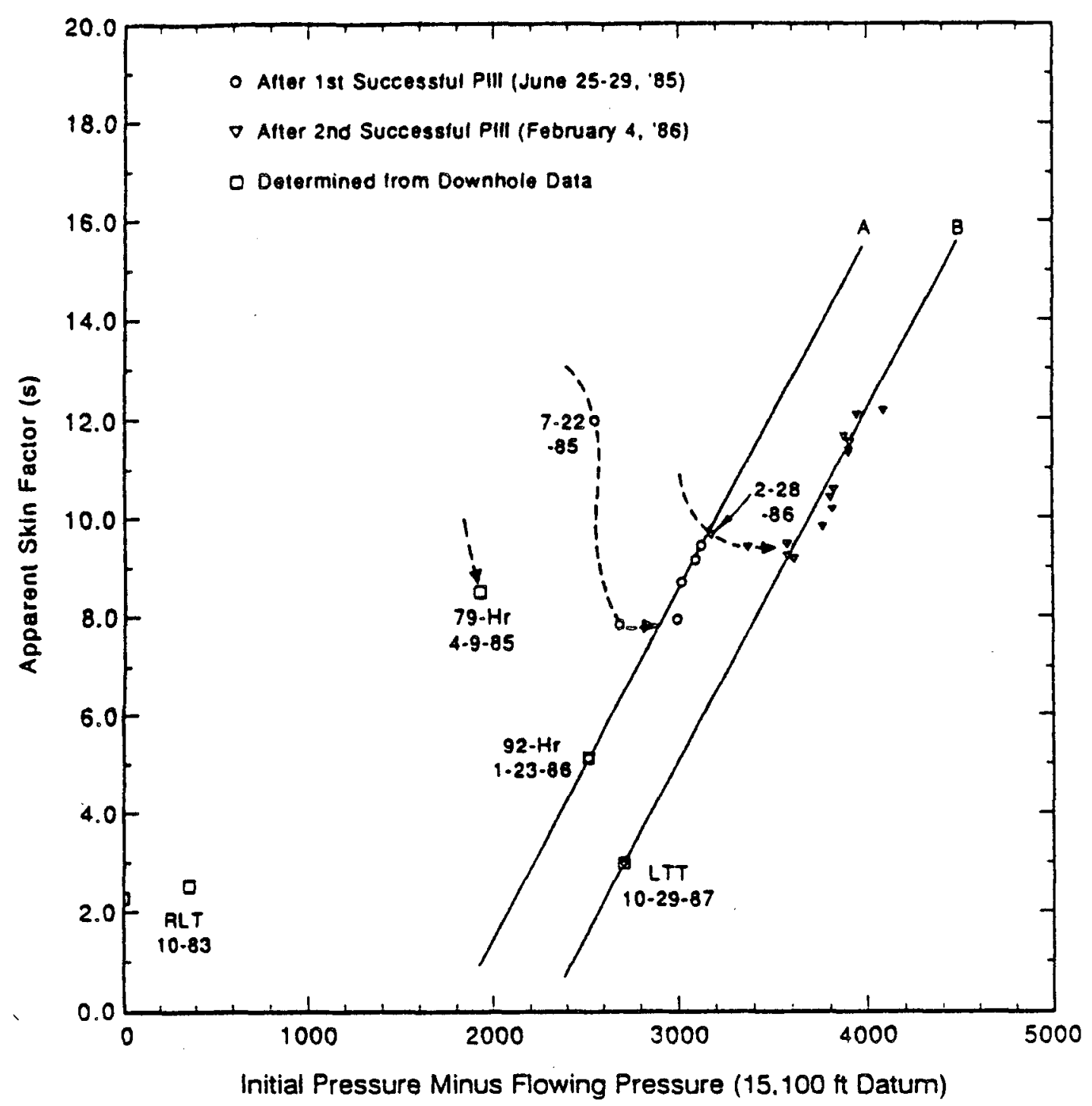

Figure 5. Apparent skin factor $(s)$ values displayed as function of pore pressure decrease (from $P_{i}=12,784$ psia) in the neighborhood of the Gladys McCall Well No. 1 wellbore.

subsequent decrease (Riney 1988). The decrease in the value of $s$ is indicated by the dashed curve approaching trend line $\mathrm{A}$ in Figure 5.

July 1985-January 1986 As bottomhole pressure continues to decrease the apparent skin factor allows trend line $A$ as shown. The skin factor $s=5.11$ determined at the time of the 92-hr buildup test falls on trend line A.

February 1986 Second successful pill injection; associated increase in apparent skin factor.

February 1986-October 1987 The apparent skin factor subsequently decreases with flow as indicated by the dashed curve approaching trend line B in Figure 5. As bottom pressure continues to change, the apparent value of $s$ follows trend line $\mathrm{B}$. The value $s=2.97$ determined at the time of the LTT shutin also falls on trend line $B$.

The fact that the estimate $s$ values approximate the trend lines A and B in Figure 5 between times that pills were injected implies that the skin factor depends on the bot- 
tomhole pressure. Based on parametric calculations performed to examine the possible effects of free gas evolution and nonlinear formation response (preceding section), the latter mechanism seems a more plausible cause for the pressure dependence. The effective tress at the sandface increases as the bottomhole pressure decreases.

In summary, it appears that there are at least three mechanisms contributing to the variations of the skin factor $s$ :

(1) Abrupt increases in $s$ associated with scale inhibitor pill injections, followed by subsequent slow decrease in $s$ by partial removal of precipitates.

(2) An apparent increase in $s$ associated with a partial penetration effect caused by reduction of the horizontal communication with the wellbore due to plugging of the formation after November 1984.

(3) An increase associated with an increase in the effective stress on the formation adjacent to the wellbore.

\section{Recalibration of Wellbore Model}

The wellbore flow model (Pritchett 1985) calculates the steady flow in a geothermal well producing under stable conditions. Starting with specified bottomhole conditions, the program integrates up the well to predict the wellhead conditions. The frictional effects in the wellbore are treated using a correlation by Dukler, Wicks, and Cleveland (1964); the effects of tubing roughness are included through a relative roughness parameter $(R)$. Heat loss by combined conduction and convection to a porous water-saturated medium is treated by an approximate analytical solutions and its magnitude is controlled by a heat transfer coefficient $(U)$. Both $R$ and $U$ are empirical parameters.

The wellbore model uses an equation-of-state for brine/methane mixtures to calculate the properties of the geopressured fluid as it rises in the productions tubing. The equation-of-state incorporates recent data concerning the compressibility of liquid brines (Osif 1984) and measurements of methane solubility in hot brines reported by Price et al. (1981). The mass fraction composition employed to represent the Gladys McCall brine is as follows:

$$
\mathrm{H}_{2} \mathrm{O}: 0.901479, \quad \mathrm{CH}_{4}: 0.003481, \quad \mathrm{NaCl}: 0.092340
$$

This choice yields a bubble point of 9200 psia for a temperature of $289.2^{\circ} \mathrm{F}$, in agreement with tests performed on reconstituted Gladys McCall sand zone 8 fluids by Weatherly Laboratories, Inc. The selected composition corresponds to GWR $=30.70$ SCF/STB, which closely approximates the total gas-to-water ratio produced from Gladys McCall Well No. 1.

Available stable downhole flowing pressure and temperature measurements in Gladys McCall Well No. 1 since October 7, 1983 (test day 0) must be used to calibrate the wellbore model. Unfortunately, the only P/T profile data were measured on April 18, 1985 (test day 549) just prior to the 79-h shut in test. Since the production tubing was badly scaled at that time, the available profile data are corrupted.

During the RLT (test day 21), a stable "full-stream" temperature of $280^{\circ} \mathrm{F}$ was recorded at the wellhead, while the temperature of the fluid leaving the separator was $275^{\circ} \mathrm{F}$. Since full-stream values were not reported after January 1985 , wellhead temperatures at the other times (79-hr, 92-hr, and LTT) are estimated by adding $5^{\circ} \mathrm{F}$ to the temperatures recorded for the fluid leaving the first stage separator. The durations of 
step $2(q=15,050 \mathrm{sep}$ b/d) and step $3(q=12,440 \mathrm{sep}$ b/d) of the multi-rate drawdown test prior to the start of the long-term shut in test were too short for stable temperatures to be attained.

Based on the reevaluation of the total pressure/temperature data available, it is apparent that the sand zone 8 temperature is higher than the value of $289.2^{\circ} \mathrm{F}$ measured at the time of the RLT. The P/T data are best matched with the wellbore model recalibrated using the earlier mass fraction composition, reservoir temperature $T_{o}=297.0^{\circ} \mathrm{F}$, and the following values for the empirical parameters: $U=7.0 \mathrm{Wm}^{-2}{ }^{\circ} \mathrm{C}^{-1}$, $R=0.090 \mathrm{~mm}$.

The new calibration has been used to estimate the pressure drop in the wellbore for a specified flow rate and pressure at the datum level, 15,100 ft. The value of $\Delta p_{\text {hydr }}$ decreases with increasing $q$ since the fluid is less dense as it has less time to cool in the wellbore at higher rates; the value of $\Delta p_{\text {fric }}$, however, rapidly increases as $q$ increases. The total pressure drop $\left(\Delta p_{w b}\right)$ decreases with increasing $q$ for $q<-3000$ sep b/d and then increases rapidly with $q$. For a fixed value of $q, \Delta p_{w b}$ decreases with a decreasing value for the datum pressure; since more gas evolves in the wellbore at the lower datum pressure, the wellbore fluid is less dense. The decrease is -125 psi as the datum pressure decreases from 12,000 to 8000 psia.

The change in datum pressure has negligible effect on the wellhead temperatures predicted by the wellbore model; the flow rate does have a significant effect. Figure 6 compares the results of the recalibrated model predictions for the wellhead temperature with the data available at times of sustained stable flow rate over the production history of the test well. The datum pressure at $15,100 \mathrm{ft}$ was fixed at 10,000 psia. The agreement is quite good. Because of the limited $\mathrm{P} / \mathrm{T}$ profile data available and lack of downhole pressure data for high flow rates, however, the calibration and associated wellbore model predictions (and consequently the estimated bottomhole pressure data points in Fig. 8) are subject to error during periods of the depletion phase when flow rates were sustained at $q \sim 20,000$ to $30,000 \mathrm{sep} b / \mathrm{d}$.

\section{Implications of Integrated Analysis}

The significant implication of the simultaneous analysis of the four pressure transient tests is the fact that the LTT infers a near-well formation transmissivity unchanged from the values inferred by the $79-\mathrm{hr}$ and $92-\mathrm{hr}$ data. It is interesting to note that the reduction in the $k h$ product from the RLT values $(28,340 / 44,090=0.64)$ is close to the hypothesized reduction in the sand thickness in horizontal communication with the wellbore $(207 / 332=0.62)$ at the time of the 79-hr test (Fig. 2).

Actual obstruction within the borehole has not been observed in later downhole probes at Gladys McCall. It is plausible that brine flow cleaned out the borehole obstruction observed on April 13,1985; scouring action appears to have occurred subsequent to each of the four pill injections (two successful and two unsuccessful attempts). After each pill injection there was a large increase in the apparent skin factor, but the magnitude of the skin effect subsequently decreased, presumably from the cleansing action of the flowing fluid. This effect might not occur in a completely plugged horizon as there is no flow; horizontal communication with the wellbore apparently has remained reduced to $-64 \%$ of its original value.

The variations in $k h$ in Table 1 would be difficult to explain in terms of nonlinear rock formation behavior. Any decrease in $k h$ would likely start at the sandface (lowest pressure/highest effective stress) and move outward as the reservoir depleted. The radial 


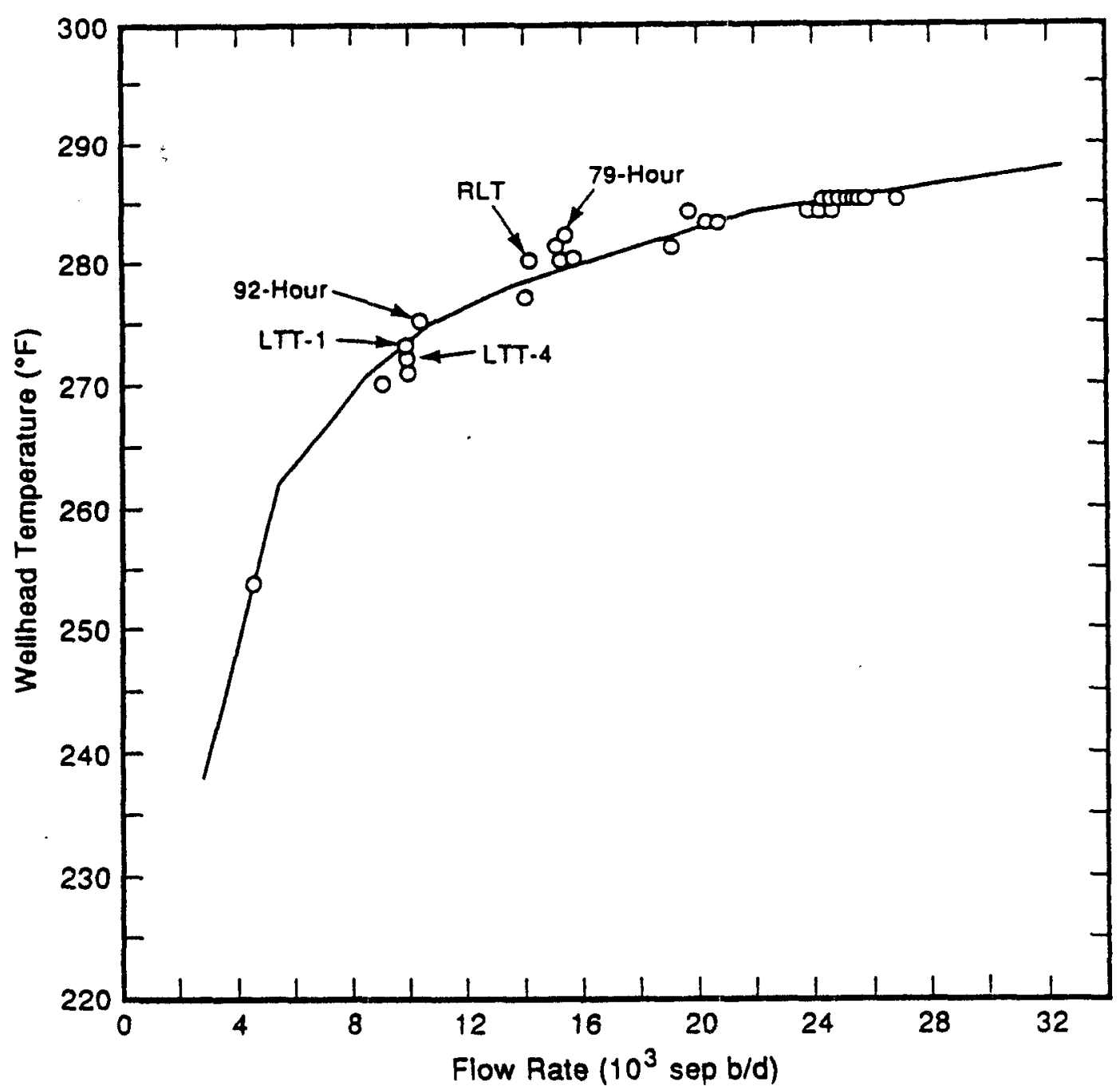

Figure 6. Stable Gladys McCall wellhead temperatures recorded during 1983-1987 (data points) at indicated flow rates compared with recalibrated wellbore model calculations (curve).

propagation of the nonlinear effect would imply a monotonically increasing apparent skin factor in association with a decreasing value for the apparent kh product (Riney 1986). It is difficult to envision a decrease in $k h$ to $64 \%$ of the original value after producing $6.8 \times 10^{6} \mathrm{sep} \mathrm{b}$ and then no further change upon producing an additional $19.4 \times 10^{6}$ sep $b$. The only significant nonlinear formation response apparent from the Gladys McCall test well data is in the immediate vicinity of the wellbore as reflected in the dependence of the skin factor on the effective stress change (Fig. 5).

Since all other downhole pressure transient measurements are consistent, it is reasonable to question the measurements made at the time of the RLT. Were the actual flow rates only $-62 \%$ of the values reported? This is not credible since the stable full-stream temperature $\left(280^{\circ} \mathrm{F}\right)$ recorded at the surface during RLT drawdown is consistent with the flow rate reported (Fig. 6). Also, the pressure drop measured in the wellbore from $15,100 \mathrm{ft}$ to the surface is consistent with the reported flow rate.

Since nonlinear formation response and measurement error do not seem plausible, the pressure transient data available from the Gladys McCall Well No. 1 are best ex- 

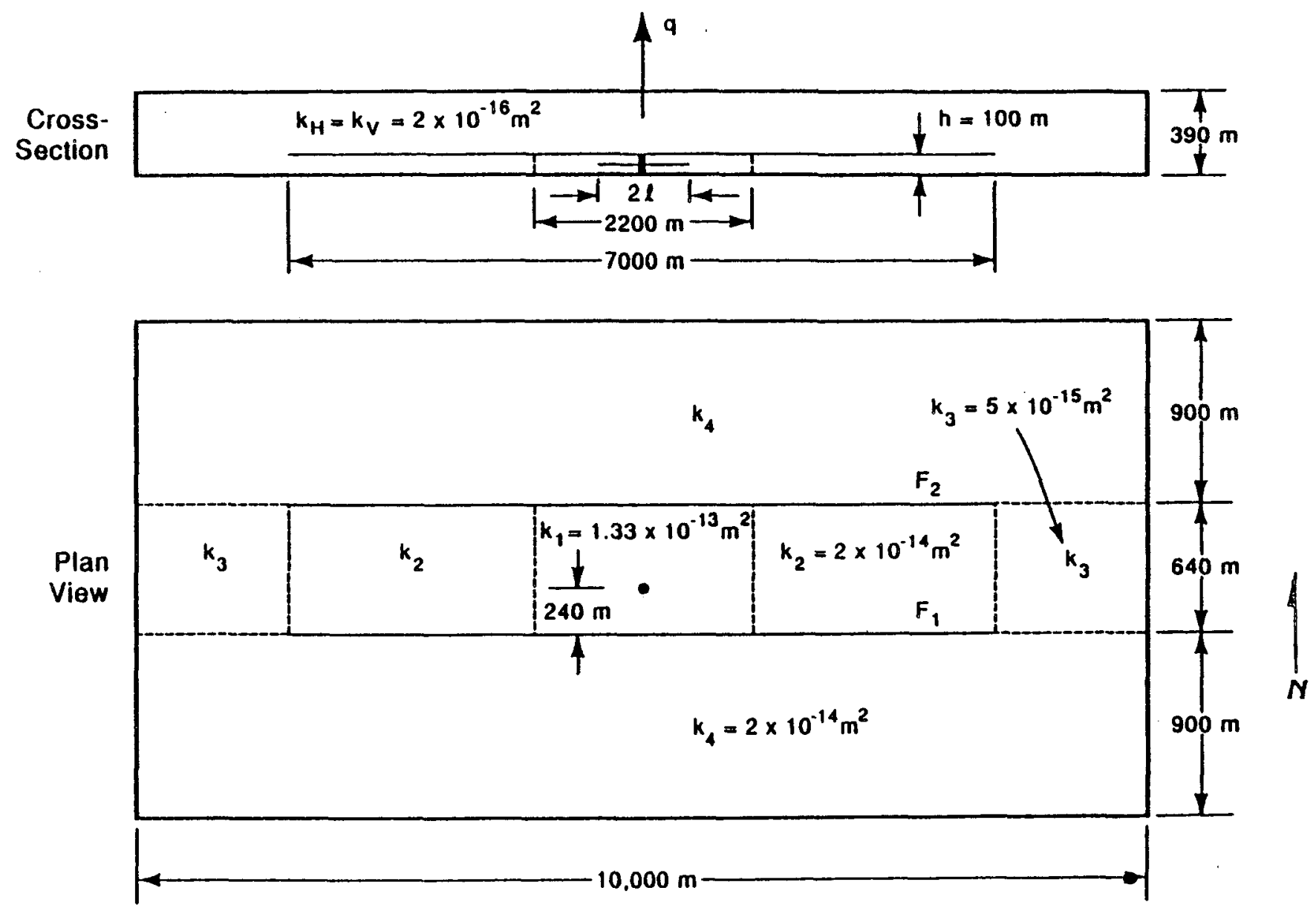

Figure 7. Vertical section (upper) and planar (lower) views of model for Gladys McCall reservoir based on concept that cross-flow from overlying/underlying sands sustain pressure in sand zone 8 ( $k_{i}=$ horizontal permeabilities in sand zone $8 ; \ell=200 \mathrm{~m}$ ). 
plained by the presumed partial plugging of the sand formation in conjunction with the presence of a thin shale stringer in sand zone 8.

\section{Reservoir Simulation Model}

Figure 7 shows a schematic of the geopressured reservoir simulation model (which employs SI metric units) used to match the integrated data sets composed of the full test history of sand zone 8 . The configuration, symmetrical across a north-south plane through the test well, is basically the same as employed in the earlier article (Riney 1988) except the total volume is enlarged by removing the earlier assumption that the flow barriers $F 1$ and $F 2$ form the southern and northern boundaries of the reservoir. The distances of F1 $(240 \mathrm{~m})$ and F2 $(400 \mathrm{~m})$ from the test well are based on the analysis of the downhole pressure data from the RLT (Riney 1988). The distance $(\ell-200 \mathrm{~m})$ that the shale stringer near the middle of sand zone 8 extends from the well is based on reservoir simulation calculations described in an earlier section. The present model assumes $62 \%$ of the thickness of sand zone 8 is above the shale stringer (Fig. 2); the earlier model used $50 \%$.

In the new model, F1 and F2 are assumed to be internal sealing faults that do not extend as far as the east-west boundaries of the reservoir. They are assumed to form horizontal flow barriers for the same distance from the test well as the major shale break at the top of sand zone 8 forms a vertical flow barrier. The north-south dimensions of the reservoir drained by the test well are assumed to extend for $2440 \mathrm{~m}$ as shown. The eastwest dimensions and the upper and lower boundaries in Figure 7, however, are unchanged from the earlier model. The thickness of $390 \mathrm{~m}$ approximates the net sand in the Miocene sand/shale sequence penetrated by the test well. The north-south and east-west dimensions roughly approximate the fault block dimensions mapped in Figure 1-

The thickness of sand zone 8 is approximated by $100 \mathrm{~m}$ as in the earlier model. The near-well horizontal permeability is chosen to be $k_{1}=134 \mathrm{md}\left(1.33 \times 10^{-13} \mathrm{~m}^{2}\right)$ to preserve the value of $k h=44,090 \mathrm{md}-\mathrm{ft}$ estimated from the RLT data. The more distant horizontal permeability in sand zone 8 is assumed to be $k_{2}=2 \times 10^{-14} \mathrm{~m}^{2}$ as in the earlier model; this permeability value is also used for the reservoir southern and northern extensions beyond faults F1 and F2 (i.e., $k_{4}=2 \times 10^{-14} \mathrm{~m}^{2}$ ). The effective horizontal permeability in the regions of the reservoir beyond the east and west ends of the faults was varied in a series of simulations; the best history match was obtained using $k_{3}=5 \times 10^{-15} \mathrm{~m}^{2}$. The total compressibility $\left(C_{T}=9.1 \times 10^{-4} \mathrm{MPa}^{-1}\left[6.27 \times 10^{-6}\right.\right.$ $\mathrm{psi}^{-1}$ ) and porosity $(\phi=0.16)$ throughout the extended sand zone 8 volume are the same as in the earlier model. The reservoir brine properties were also unchanged: $\mu=$ $0.31 \times 10^{-4} \mathrm{~Pa}-s(0.31 \mathrm{cp}), \rho=1030.5 \mathrm{~kg} / \mathrm{m}^{3}$.

The 290- $\mathrm{m}$ thick upper layer in the model represents overlying/underlying sands that contribute to the pressure support of sand zone 8 by fluid cross-flow at shale breaks.- $-\cdots$. Both the horizontal and vertical effective permeabilities in this layer and the vertical permeability in sand zone 8 are all assumed to be $2 \times 10^{-16} \mathrm{~m}^{2}$. The total compressibility is the same as in sand zone 8 , but the porosity was reduced to $\phi=0.12$ in this "remote volume" to provide the best history match.

It should be emphasized that the actual reservoir properties away from the test well are not known and our choices represent "effective values" that provide a good match to the integrated depletion and recovery phases of Gladys McCall Well No. 1.

In simulating the production history of the well, the numerous rate changes were closely approximated. The values of the skin factor $(s)$ determined from the wellhead 
pressures in Figure 5 were employed in the simulation. At $t \sim 418$ days (November 28 , 1984), plugging by the first aborted pill injection of the portion of sand zone 8 below the shale stringer is assumed; flow into the wellbore thereafter is restricted to the upper 207 $\mathrm{ft}$ (Fig. 2) so that the near-well apparent transmissivity is reduced to $k h=28,340 \mathrm{md}$ - $\mathrm{ft}$. Figure 8 compares the simulated sandface pressure at the datum level $(15,100 \mathrm{ft})$ with bottomhole values estimated from wellhead recordings during periods of stable production. The stimulated sandface pressure agrees equally well with bottomhole values estimated from wellhead recordings just after planned shut ins $\left(\left[p_{w s}\right]_{3 m}\right)$. There is also good agreement through the simulated transition from the depletion phase to the recovery phase during the four-week period starting on April 21, 1987. The simulated sandface pressures during the multi-rate flowing portion of the LTT and the shut-in portion of the LTT are compared with the bottomhole data (corrected to the datum level) in Figures 3 and 9 , respectively.

\section{Discussion}

Nonlinear reservoir response mechanisms have not been detected at Gladys McCall except possibly as a skin effect in the vicinity of the wellbore. Nevertheless, nonlinear processes (e.g., irreversible formation compaction, shale water influx, leaky boundaries, formation creep, etc.) might be present and have affected long-term pressure maintenance but be too subtle to be apparent in the test data from a single well in a poorly defined reservoir. This would be in contrast with the experience at the Parcperdue geopressured reservoir where robust nonlinear effects were manifested from the early short-term testing of the L. R. Sweezy well.

A simple reservoir configuration (Fig. 7) has been used as a framework for constructing a linear model to match the integrated data base available for Gladys McCall. The reservoir boundaries were chosen such that total fault block volume roughly approximates the dimensions suggested by the limited geological information and the near-field reservoir properties are based on data from the test well. The configuration used is only one of many alternatives, however, and is not particularly constrained by the geological data. The unknown far-field reservoir properties were varied in a series of parametric calculations to arrive at values that provide a good match to the available test data. The quality of the history match obtained during the transition from the depletion to the recovery phase was sensitive to the parameters that control the hydrologic connection to the remote volumes of the reservoir. The value chosen for the effective porosity in the reservoir volume representing the overlying/underlying stands affects the quality of the history match during the recovery phase.

The good match that the simulation model provides with the integrated data base does not imply that the selected configuration approximates the actual reservoir geology or that the far-field reservoir properties approximate the actual values. It only suggests that the depletion and recovery behavior of the real system is similar to that of the model selected. This non-uniqueness problem cannot be resolved in the absence of more definitive information defining the geology and reservoir properties away from the Gladys McCall test well.

The connected pore volume of the linear (but heterogeneous) reservoir model used to match the integrated Gladys McCall data is

$$
V_{p}=10,000(2440)[(0.16)(100)+(0.12)(290)]=1.24 \times 10^{9} \mathrm{~m}^{3}\left(7.8 \times 10^{9} \mathrm{bbl}\right)
$$




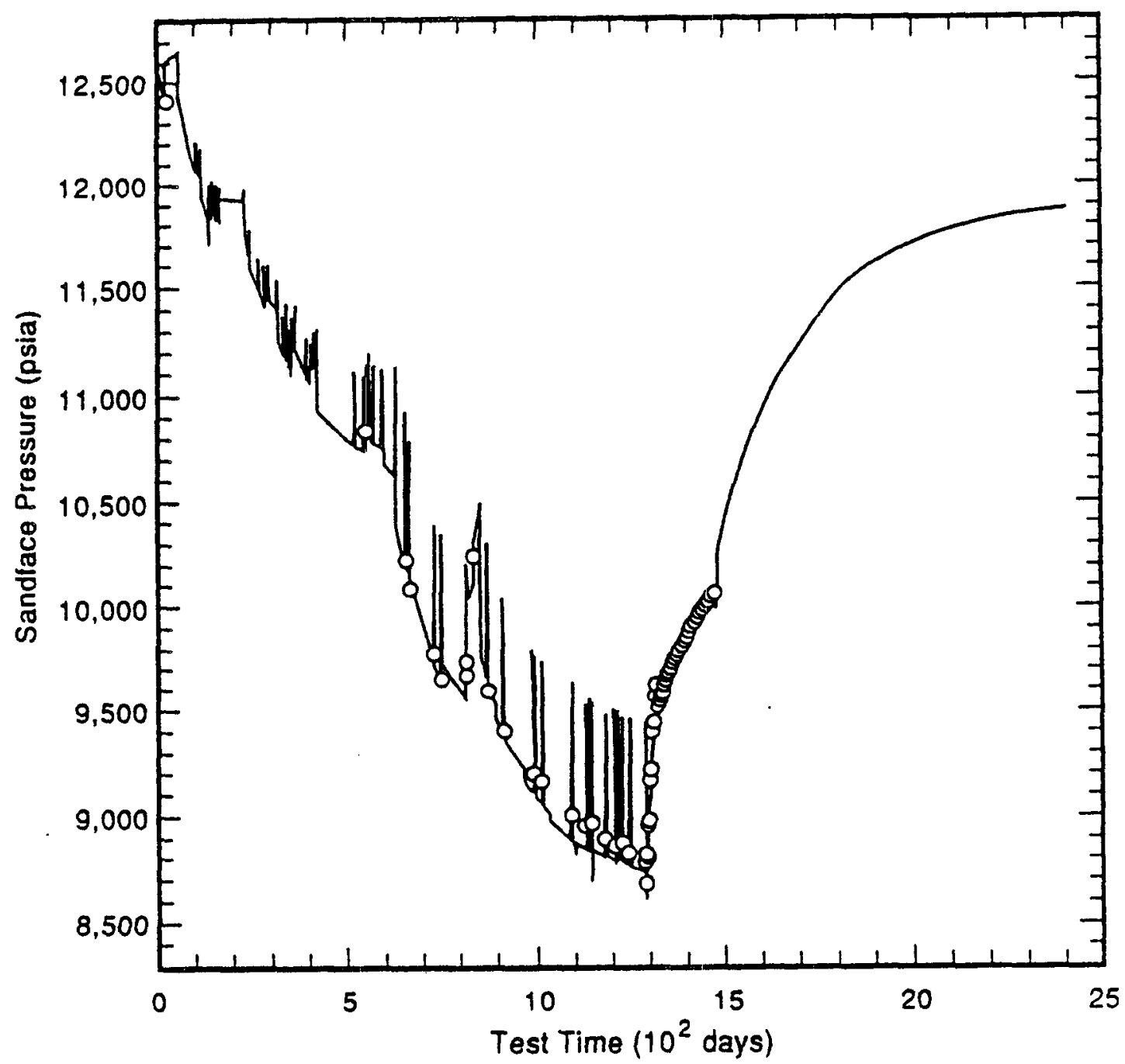

Figure 8. Simulated sandface pressure history (curve) compared with values (points) estimated from flowing wellhead recordings of Gladys McCall Well No. 1 . Datum level is $15,100 \mathrm{ft}$.

Since estimates for distances made from well test analysis depend on the square root of $C_{T}$, all lateral dimensions employed in the model would need to be increased by $\sim 20 \%$ if $C_{T}=4.0 \times 10^{-6} \mathrm{psi}^{-1}$ were used, or decreased by $\sim 10 \%$ if $C_{T}=7.7 \times 10^{-6} \mathrm{psi}^{-1}$ were used, rather than $C_{T}=6.27 \times 10^{-6} \mathrm{psi}^{-1}$. These dimensions would also lie within the uncertainty of the known geology of the Gladys McCall fault block.

In contrast with the situation at Gladys McCall, the geological information for the geopressured C-zone being tested by the Pleasant Bayou research well is extensive. Considerable deep-well data and broad-based geological work has defined the boundaries and internal structure of the reservoir and estimated the connected pore volume to be between 6.2 and $6.6 \times 10^{9} \mathrm{bbl}$ (Hamlin and Tyler 1988). Long-term production testing of the Pleasant Bayou well, now in progress, will provide a basis for comparing geopressured reservoir volume estimates based on extensive geological data as opposed to estimates based on actual depletion behavior of the reservoir. These results may provide further insight for interpreting the Gladys McCall test data. 


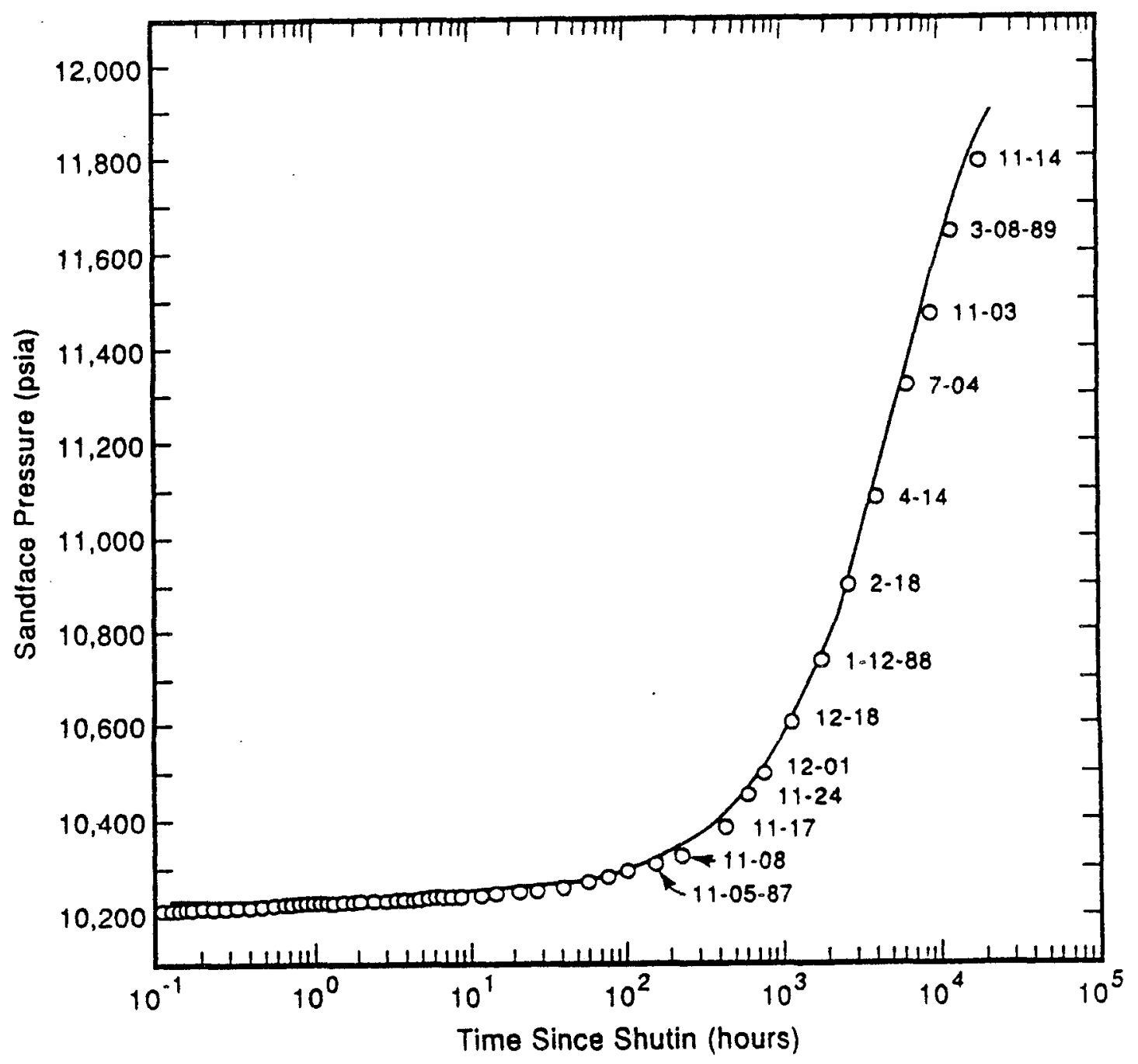

Figure 9. Simulated pressure buildup history (curve) compared with bottomhole pressure data (points) measured during long-term shut in test still underway at Gladys McCall Well No. 1. Datum level is 15,100 feet.

\section{Acknowledgment}

This work was sponsored by the U.S. Department of Energy and performed under subcontract to the University of Texas at Austin (Cooperative Agreement No. DEFC07$85 \mathrm{NV} 10412$ ).

\section{References}

Bebout, D. G. 1982. Regional and local geologic setting of the technadril-Fenix and ScissonDepartment of Energy Gladys McCall No. 1 Well Site. In Geopressured-geothermal energy resource appraisal, Guidebook No. 2, Louisiana Geological Survey, pp. 49-71.

Bebout, D. G., R. G. Loucks, and A. R. Gregory. 1978. Frio sandstone reservoirs in the deep subsurface along the Texas gulf-coast-Their potential for the production of geopressured geothermal energy. The University of Texas at Austin, Bureau of Economic Geology Report 91.

Brunheld, S. R. 1984. Depositional and structural reconstruction of southwestern Louisiana 
Oligo-Miocene strata: A temporal spatial approach. Transactions of the Gulf Coast Association of Geological Societies 34:9-31.

Dukler, A. E., M. Wicks III, and R. G. Cleveland. 1964. Frictional pressure drop in two-phase flow-B: An approach through similarity analysis. AIChE. J. 10:44.

Durrett, L. R. 1985. Results of long-term testing of a geopressured-geothermal design well, T-F\&S/DOE Gladys McCall No. 1. In Proceedings of Sixth U.S. Gulf Coast GeopressuredGeothermal Energy Conference, The University of Texas at Austin, February 4-6.

Earlougher, R. C., Jr. 1977. Advances in well test analysis. Monograph No. 5, Dallas, Texas: Society of Petroleum Engineering of AIME.

Garg, S. K., T. D. Riney, and R. H. Wallace, Jr. 1985. Brine and gas recovery from geopressured systems. Geothermics 15:23-48.

Hamlin, H. S., and N. Tyler 1988. Consolidation of geologic studies of geopressured-geothermal resources in Texas. Annual Report under U.S. Department of Energy and the University of Texas at Austin Cooperative Agreement No. DE-FC07-85NV 1041, December.

John, C. J. 1988. Geology of the Gladys McCall geopressured prospect, Cameron Parish, Louisiana. Journal of Energy Technology, ASME 110:255-261,

Kelkar, S., C. Coley, J. Schatz, and T. Boeschel. 1982. Core handling, testing and analysis for DOE/T-F\&S Gladys McCall No. I Well, Cameron Parish, Louisiana. Terra Tek, Inc. Report TR 82-64, September.

Osif, T. L. 1984. The effects of salt, gas, temperature and pressure on the compressibility of water. Society of Petroleum Engineering Paper No. 13174, September.

Price, L. C., C. W. Blount, D. MacGowan, and L. Wenger. 1981. Methane solubility in brines with application to the geopressured resource. In Proc. Fifih Conference on GeopressuredGeothermal Energy, Louisiana State University, Louisiana, pp. 205-214, October.

Pritchett, J. W. 1985. WELBOR: A computer program for claculating flow in a producing geothermal well. S-CUBED Report SSS-R-85-7283.

Riney, T. D. 1986. Simulation of irreversible rock compaction effects on geopressured reservoir response. Topical report under U.S. Department of Energy and The University of Texas at Austin Cooperative Agreement No. DE-FC07-85NV 10412, December.

Riney, T. D. 1988. Gladys McCall geopressured reservoir analysis-June 1987. Journal of Energy Technology, ASME 110:262-268.

Technadril-Fenix and Scisson. 1982. Geopressured-geothermal drilling and testing plan: T-F\&S/ DOE Gladys McCall No. I Well, Cameron Parish, Louisiana. Vol. II-Testing Plan, U.S. Department of Energy, Nevada Operations Office, Report No. NVO-229, January.

Tomson, M. B., J. M. Matty, and L. R. Durrett. 1985. Saturation index predicts brines scaleforming tendency. Oil and Gas Journal 83:97-108. 